\title{
PART I. OPHTHALMOSCOPIC AND CIRCULATORY CHANGES IN FOCAL RETINAL ISCHAEMIA
}

\author{
BY
}

\author{
C. T. DOLLERY, P. HENKIND, J. W. PATERSON, \\ P. S. RAMALHO, AND D. W. HILL
}

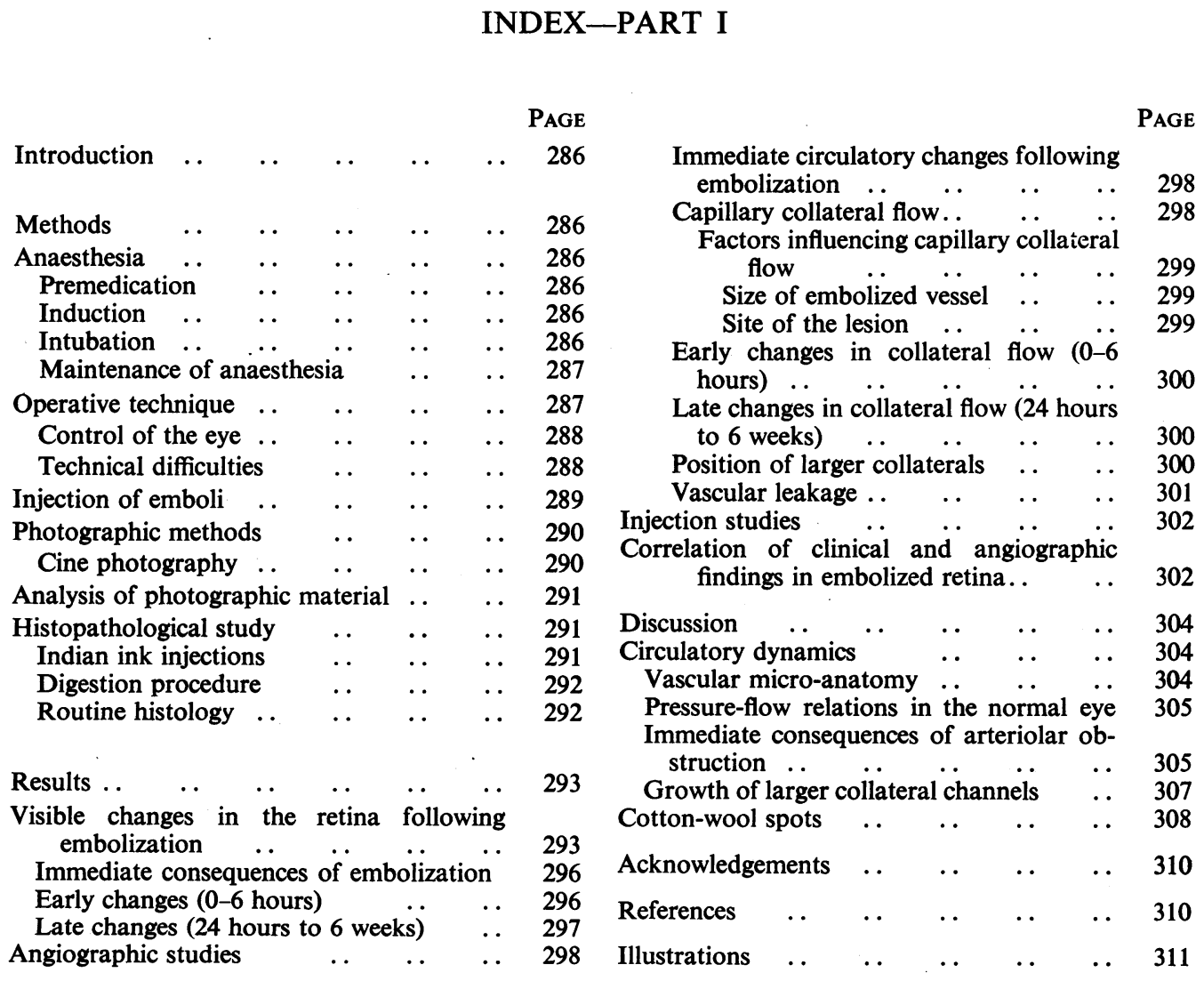




\section{INTRODUCTION}

IN previous reports (Ashton and Henkind, 1965; Dollery, Ramalho, Paterson, Hill, Henkind, Shakib, and Ashton, 1965) we demonstrated the profound effects which occur in the retina of experimental animals following arteriolar embolization. Our initial endeavour was to delineate the variety of pathological responses to embolization with inert material, for these had not been fully studied in the past. The lesions produced included among others, "cotton-wool" patches, retinal atrophy, pre- and intra-retinal haemorrhages, arteriolar and venous collaterals, and retinal neovascularization in the kitten. All were clearly dependent upon alterations in the retinal microcirculation, and thus there was an obvious need to study this vascular bed and its responses. Fortunately techniques were available for studying the circulation of the retina in the intact eye, and these allowed definition even at the capillary level. Herein we correlate the circulatory dynamics of the retina as studied in vivo by fluorescence fundus photography with observable fundus lesions studied both clinically and microscopically. In addition the present study sheds light on the pathogenesis of "cotton-wool" spots and it demonstrates conclusively the importance of capillary collaterals following embolization and their role in the later formation of larger calibre collaterals.

\section{METHODS}

The animals used in these studies were white pigs bred commercially. At the start of the experiment they weighed between 29 and $66 \mathrm{lb}$. but they gained weight rapidly. One animal that weighed $31 \mathrm{lb}$. on admission weighed $103 \mathrm{lb}$. six weeks later. All the animals were healthy and had only mild infestation with ectoparasites which was eliminated with insecticides.

\section{Premedication}

\section{Anaesthesia}

Initially the animals were premedicated with diethylthiambutene $1 \mathrm{mg} . / \mathrm{lb}$. and atropine $0.6 \mathrm{mg}$. However, there did not appear to be any advantage in this and there was a tendency for tachycardia to develop, probably due to the atropine, as reported by Guiney (1965). In subsequent studies no premedication was given and induction was performed without difficulty if the animal was kept blindfolded.

\section{Induction}

Induction was performed with intravenous 5 per cent. sodium thiopentone injected through an ear vein. The dose varied from $5 \mathrm{ml}$. to $20 \mathrm{ml}$. and was injected slowly, not more than 1-2 ml. per minute. If too much was given profound apnoea ensued and unless intubation was speedy adequate ventilation was impossible, as a suitable mask to fit the pig's face was not available.

\section{Intubation}

This was found to be the most hazardous part of anaesthesia in pigs. After induction the animal was laid on its left side. The jaws were held open with leather thongs and the cords visualized with a straight-bladed laryngoscope. Lignocaine 
1 per cent. was then sprayed on the cords. A cuffed endotracheal tube (size 5-8 depending on the size of the pig) containing a copper wire to stiffen it was passed between the cords. The pig is more difficult to intubate than other experimental animals, such as the dog, because the neck is short and thick and the larynx is angulated posteriorly (to the right with the animal on its left side) at the level of the cords. The tube was passed towards the cords with the end curved to the left and just as it passed through was turned through $180^{\circ}$ which helped to accommodate the angulation. If great care was not taken at this point it was possible to rupture blood vessels just lateral to the cords in the pyriform fossa, or even to pass the tube through the anterior wall of the larynx below the cords. Laryngeal spasm was easily induced and could be severe enough to necessitate a tracheostomy. Succinyl choline would relax the cords but unless intubation was speedy adequate ventilation could not be achieved, and Guiney (1965) found that even by using succinyl choline tracheostomy was not always avoided. Factors involved in the development of laryngeal spasm were the depth of anaesthesia and inadequate application of lignocaine to the cords.

\section{Maintenance of Anaesthesia}

The endotracheal tube was attached to a Boyle's machine with a closed circuit and soda-lime absorber. A mixture of oxygen and nitrous oxide in the ratio $1: 2$ (either 1 litre $\mathrm{O}_{2}$ and 2 litres $\mathrm{N}_{2} \mathrm{O}$ or 0.5 litre $\mathrm{O}_{2}$ and 1 litre $\mathrm{N}_{2} \mathrm{O}$ per minute) was used, and to this was added 0.5 to 1.5 per cent. halothane according to the state of the animal. Respiration and heart rate were recorded frequently, and the average range for healthy animals was respiration $15-35$ per minute and heart-rate 90-180 per minute. On occasions where a blood-pressure recorder was not available a crude idea of cardiovascular status could be obtained by palpation of the pulse at the distal end of the forelimb (analogous to the radial pulse in man). Anaesthesia had to be closely observed, especially during manipulation of the carotid and injection of emboli, as apnoea could occur and if hand ventilation was not instituted cardiac arrest would follow. Usually, after four to five hours of anaesthesia the animal's condition began to deteriorate, especially if several injections of ballotini had been given.

\section{Operative Technique}

An incision approximately $8 \mathrm{~cm}$. long was made longitudinally in the pig's neck just to one side of the trachea. The neurovascular bundle containing the common carotid artery, vagus nerve, and internal jugular vein lies deep in the groove between the trachea and the sternomastoid muscle. The muscle was retracted laterally and the artery exposed by dissecting away a thin overlying sheet of muscle. The artery was freed with as little trauma as possible, because it easily went into spasm. It was punctured with a sharpened piece of steel wire $30 \mathrm{~cm}$. long which was threaded through a 20-cm. length of gauge 00 nylon tubing $0.5 \mathrm{~mm}$. in diameter. The nylon tubing had been specially prepared so that it fitted the wire closely at its pointed end.

After the artery had been punctured the nylon tube was pushed forward over the wire until several centimetres lay within the lumen. The steel guide wire was withdrawn and a fine needle-butt fitted to the end of the nylon tube. The tube was kept 
full of heparinized saline $(1,000$ units in $250 \mathrm{ml}$.) when not in use. This method allowed the introduction of the nylon catheter into the artery with a minimum of interference and did not obstruct flow through the vessel. It was important not to puncture the back wall of the carotid artery as bleeding into the wall took place readily and could obstruct the flow.

At the end of each study the nylon tube was withdrawn from the artery and bleeding controlled by compression applied for 5 minutes. The wound was closed with a number of deep sutures to obliterate the space as a haematoma forms easily in this loose tissue. In two studies the tube was left in the artery, with its lumen blocked and its end buried beneath the skin. However, the fine nylon catheter worked its way out of the artery as it could not be tied in, and in subsequent studies a fresh puncture was made on each occasion. When it was not necessary to inject emboli the artery was usually punctured with a fine needle fitted to the end of a length of P.E. 60 polyethylene tubing.

\section{Control of the Eye}

The pupil was dilated by administering drops of 0.5 per cent. cyclopentolate and 10 per cent. phenylephrine into the conjunctival sac. The lids were retracted by inserting a stay suture through each and in many studies a tarsorrhaphy was also performed.

Control of the position of the eye during photography was a problem. Sutures were inserted into the tendinous insertions of the four rectus muscles. These sutures lay at the four quadrants approximately $90^{\circ}$ from one another. In the earlier studies clips were attached to these sutures and an attempt was made to control the position of the eye by varying the tension applied to each, but this method proved unsatisfactory. Later a special ring was designed which had four manipulators mounted on it. Each manipulator was in a ball and socket joint and could be positioned at any angle, and could also be retracted and extended. The tip of each manipulator was secured to the globe by the sutures inserted in the muscle tendons. Using this device it was possible to fix the eye in a fairly wide range of positions without undue tension. An irrigator was also fitted to the ring so that the cornea could be kept moist with 0.9 per cent. sodium chloride solution.

\section{Technical Difficulties}

On some occasions difficulty was encountered because clouding of the cornea occurred before the experiment was complete. In all instances this could be traced to failure to keep the cornea moist throughout the study. Two out of 27 animals studied had bilateral cataracts when the animal was admitted, and although they were not severe they made high definition studies of the retinal circulation impossible.

Some difficulties were encountered with the positioning of the carotid artery catheter. If this was passed to a more distal position in the carotid tree it sometimes entered a branch which did not supply the eye. Withdrawal of the catheter a few centimetres usually sufficed to locate it in the common or external carotid artery. In three studies where the carotid artery was damaged during catheterization no dye entered the retinal circulation despite repeated injections. The artery was not 
completely obstructed because blood could be withdrawn freely through the catheter, but we suppose that the balance of flow distribution between the left and right carotid artery territory had been disturbed because of the partial obstruction of the artery on the side being studied. When this happened it is possible that the principal arterial contribution to the ipsilateral eye came from the contralateral artery.

\section{Injection of Emboli}

The position of the carotid artery catheter was checked by the injection of sodium fluorescein dye through it into the artery. If the catheter was correctly positioned the dye appeared in the retinal vessels within about 2 seconds. A double appearance of dye separated by about $1 \frac{1}{2}$ seconds was observed when the injection was made into the common carotid artery. Usually control colour or fluorescence photographs were taken of the nasal area of retina, which was convenient to photograph and an easy region to embolize. Glass microspheres* grade 15,18 , or 20 , ranging from approximately 15 to $90 \mu$ in diameter were suspended in $5-10 \mathrm{ml}$. of gum arabic. The grade used varied in different experiments, but many were done with sieved grade- 20 spheres with a size range of $15-40 \mu$. The emboli were injected slowly through the carotid catheter while the retina was observed so that their arrival could be noted. The number of emboli entering the retina varied widely and unpredictably. On some occasions 20 or 30 emboli entered the area of study on the first injection, while on others 7 or 8 injections were required before any emboli were seen. Emboli tended to pack the butt of the needle which led into the nylon catheter and they sometimes blocked it completely at this point. This did not matter as the needle could be replaced and the catheter itself never became blocked. Ninety-five injections of emboli were made. On seven occasions an animal became temporarily apnoeic after an injection.

In earlier studies, before this hazard was appreciated, cardiac arrests took place on four of these occasions. It proved possible to resuscitate the animals by a brief period of ventilation with oxygen and external cardiac massage. Later, when special care was taken to maintain ventilation immediately after embolization, this type of incident no longer occurred. Deterioration in the general condition of the animal was noted when multiple injections of emboli had to be given. The respiration became shallow and fast and the heart rate increased, sometimes with a fall in blood pressure.

As soon as the emboli were located in the retina colour and fluorescence photographs were taken and these were repeated at intervals for up to five or six hours. Attempts to continue the acute observations beyond six hours did not prove successful as animals anaesthetized for this period of time deteriorated and died. Most acute studies were continued for only two or three hours, when the experiment was either terminated or the wound was closed, the eye sutures removed, and the animal allowed to recover consciousness.

The animals recovered rapidly from anaesthesia and only one showed a definite neurological deficit. This animal had a mild right hemiparesis which recovered in

* The English Glass Company, Scudamore Road, N.P.E., Leicester, England. 
24-48 hours. One reason why the majority had no neurological deficit may be that the emboli were injected largely into the territory of the external carotid artery which does not supply the brain.

\section{Photographic Methods}

Colour photographs were taken on $35-\mathrm{mm}$. Kodachrome II film to document the evolution of the retinal changes.

Fluorescence angiograms were taken using Ilford HPS film (ASA 800) which was force-developed (Dollery, Hodge, and Engel, 1963). To facilitate photography a Nikon F 35 motor-driven camera was used in conjunction with a specially constructed 350 -joule electronic flash unit which recharged in only 0.9 seconds.

Some modifications were necessary in the standard Zeiss retinal camera to make possible the use of the Nikon. A special adapting ring was used to clamp the Nikon to the retinal camera and the reflex viewing eyepiece of the latter was lengthened to keep the path-length to both film and eyepiece the same. This modification was necessary because of the greater thickness of the Nikon than the Contax it replaced. A microswitch was fitted into the retinal camera eyepiece and arranged to close after the reflex mirror was fully depressed. This switch controlled the relay firing of the Nikon camera. A further relay was incorporated in series with this circuit which broke each time the electronic flash fired and made when it recharged. The Nikon camera takes a photograph when its control relay is closed and winds on when it is opened. Thus, once the retinal camera reflex mirror has operated the microswitch the first picture is taken, and if the mirror is kept depressed the electronic flash unit relay makes and breaks the circuit, each time taking a picture, as soon as the condensers are recharged. A separate pair of contacts on the relay actuates a chart recorder so that the timing can be read off.

\section{Cine Photography}

Cine photographs were taken using an electrically driven Bolex $\mathrm{R} 16,16-\mathrm{mm}$. reflex cine camera. The camera was used with a Wray F $1 \cdot 0$, M $0: 33$ copying lens and was placed on an extension tube above the eyepiece assembly (Fig. 1). Reflex viewing was possible through the cine camera while it was in use. The green filter used for fluorescence work was built into the extension tube but could be withdrawn on a slide.

Important modifications to the illuminating system were necessary for cine photography. An electronic flash unit was tried which gave a 25 -joule flash every $\frac{1}{16}$ th of a second. This was synchronized with the camera shutter by a rotating perforated disc attached to the cine camera drive-spindle and passing in front of a photodiode connected to a pulse-shaping unit. Though this system worked, the light output was barely adequate.

An XBO 150/W1 high-pressure Xenon lamp proved to be the most satisfactory means of achieving the required light output. The flash tube built into the retinal camera was removed and a heat-resistant glass filter fitted over the condensing lens. Air-blast cooling was supplied by two jets clamped to the aperture into which the flash tube normally fits. The XBO 150/W1 lamp was fitted horizontally through 


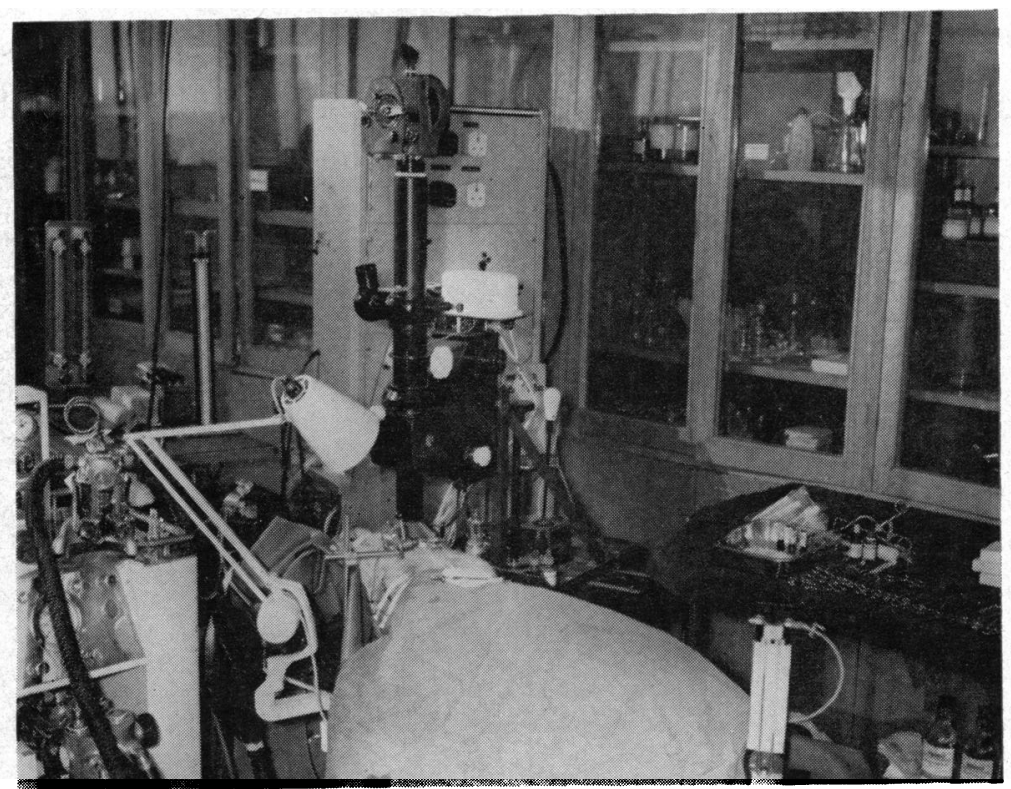

Fig. 1.-Apparatus in use for cine fluorescence angiography of the pig retina. The $16-\mathrm{mm}$. cine camera is on an extension tube above the vertically mounted Zeiss fundus camera. The power units and anaesthetic apparatus are in the background.

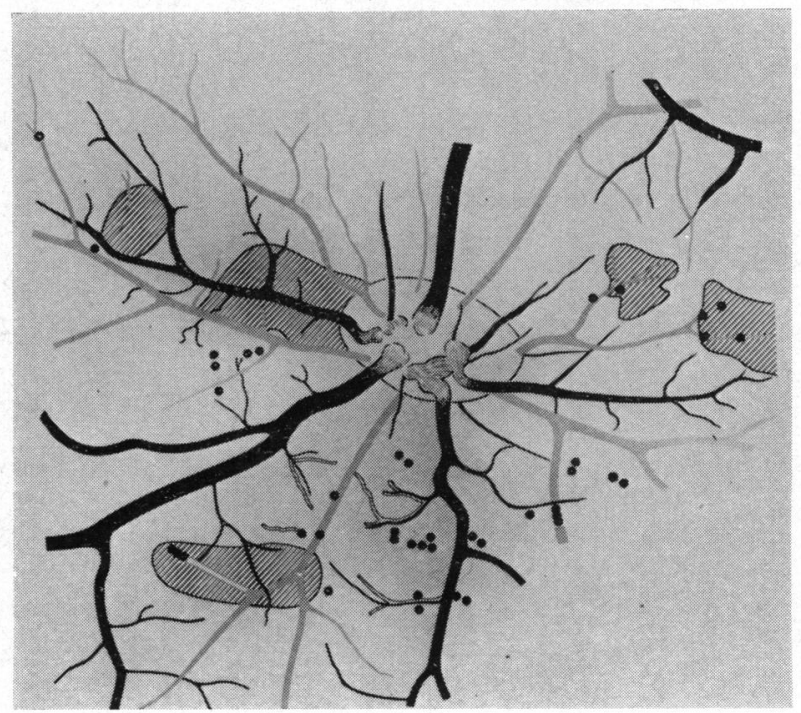

FIG. 2-A diagram of the optic disc region of a heavily embolized pig retina. Arteries are shown as grey lines and veins as black lines. The black dots show the position of the emboli and the cross-hatched zones represent areas of greyish-white discoloration. 
holes cut in the side of the retinal camera. It was mounted in such a way that the position could be adjusted by a screw-drive to achieve optimal illumination of the fundus. The trigger unit for the Xenon lamp was mounted above the lamp housing on the retinal camera. Cooling was supplied by an air compressor giving an output of 170 litres a minute. Efficient cooling is imperative as the quartz lamp envelope is only a few millimetres from the first condensing lens of the camera. It also proved necessary to cool the blue filter in the light beam with a subsidiary air jet, otherwise bubbles appeared in the gelatine. The manufacturers state that the XBO 150/W1 lamp should be mounted within $15^{\circ}$ of vertical, but it has withstood more than 200 starts in the horizontal position without evident harm. The great advantage of the high-pressure Xenon lamp is that it gives full power immediately and there is a reasonable output in the blue region of the spectrum. As there is a high resting pressure in the lamp, even when it is cold, it must be handled with great care, and if the envelope is exposed the operator must wear protective goggles. Because of the heating effect the lamp was ignited for only 15-30 seconds for each dye injection.

Cine films were processed in the same manner as the 35-mm. HPS which required the use of a special processing unit* so that the film could be force developed. Prints were made from the master negative by standard commercial methods.

\section{Analysis of Photographic Material}

All the photographs, both colour and fluorescence, were examined carefully and reported. The colour photographs were projected on to the bench and a detailed outline drawing was made to show the position of all the emboli and their relationship to other features. The emboli were numbered (more than one glass sphere packed close together was counted as one), as were grey patches, cotton-wool spots, and haemorrhages. A drawing showing some of these features is illustrated in Fig. 2.

The fluorescence photographs were examined for evidence of collateral flow, and where possible a measurement of the speed of blood flow through the collaterals was made. This could be done simply where the main arteriole filled retrogradely from the periphery and the dye front could be followed in a sequence of timed pictures. In some cases this was not possible and a contour map of the collateral in-filling was drawn. Each line represented the movement of dye front over a timed interval and the distance between the lines gave an approximate estimate of the velocity of collateral flow.

Estimates of collateral blood flow and of the normal forward velocity of flow in the retinal arterioles were also made by frame analysis of $16-\mathrm{mm}$. cine films. The colour and fluorescence photographs were compared by projecting one transparency on to a drawing or print of the other.

\section{(1) Indian Ink Injections}

\section{Histopathological Study}

A 3-mm. bore plastic cannula was tied into the common carotid artery on one side and this was attached to an A.E.I. roller blood-pump which first circulated $0 \cdot 2$ per cent. sodium nitrite to flush the vessels. Stock Indian ink was then circulated at

\footnotetext{
* Hanssen, supplied by Ilford Ltd., Ilford, Essex, England.
} 
physiological pressures until the retinal vessels on the ipsilateral side filled with ink as determined by direct ophthalmoscopy. The eyes were then enucleated and placed in 10 per cent. formol saline for 24 hours. After fixation the globes were sectioned coronally at the posterior portion of the ciliary body near the ora serrata, and the retina was gently teased free from the underlying choroid. The vitreous, which stuck tenaciously to the inner surface of the retina, had to be cut with scissors and removed with a camel-hair brush. Radial incisions extending for several millimetres were made at approximately 12,4 , and 8 o'clock positions and the retina was smoothed flat and mounted in glycerine jelly.

\section{(2) Digestion Procedure}

Segments of retina, as well as intact whole retinae, were digested by both the trypsin (Kuwabara and Cogan, 1960) and pepsin-trypsin (Ashton, 1963) techniques. Neither procedure gave good results on freshly fixed material and only in one instance where the globe was not fixed for several hours did the retina digest well.

\section{(3) Routine Histology}

Routine cross-sections of the pig's eye were prepared after fixation in formol saline. In addition, a number of retinal segments with obvious pathological changes were removed and stained for fat with oil red $O$. Thin sections from Eponembedded blocks were also prepared and stained with toluidine blue.

\section{RESULTS}

In all, 27 pigs were studied for periods ranging from 1 hour to 6 weeks after embolization. In 8 animals where prolonged studies were made of one eye the opportunity was taken to perform a short-term study on the other on the last day of the experimental period. Altogether 35 eyes were therefore available for study. The acute studies were usually continued for only 2 to 3 hours although in two instances they were prolonged for up to 6 hours. Repeat studies were made at intervals chosen to give a representative analysis of the sequence of events that followed embolization and they were to some extent governed by the ophthalmoscopic appearances visible on examination of the conscious animal. At the conclusion of each study the eyes were removed under anaesthesia for pathological examination and either fixed for routine examination or for electron microscopy (see Table). The photographic material alone was vast. More than 1,000 colour photographs, 2,000 fluorescence photographs, and 2,000 feet of cine film were examined. More than 300 emboli, or groups of emboli, were studied.

The results will be dealt with under four main headings: (1) Visible changes in the retina following embolization. (2) Angiographic studies. (3) Injection studies. (4) Correlation of clinical and angiographic findings in the embolized retina.

\section{Visible Changes in the Retina following Embolization}

The normal pig retina has a fairly close resemblance to that of man. Up to ten separate arteries arise from the optic disc (Fig. 2), but there are usually three or four main channels. The most prominent of these is a large superior artery. The 
FOCAL RETINAL ISCHAEMIA

\begin{tabular}{|c|c|c|c|c|c|c|c|c|c|c|c|c|c|c|c|c|c|c|}
\hline$\sum_{\dot{\mu}}^{\dot{j}}$ & $\sum_{\text {山् }}$ & $\sum_{\dot{\mu}}$ & 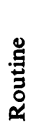 & $\sum_{\dot{\omega}}$ & 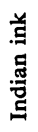 & 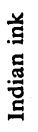 & 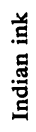 & 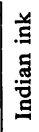 & 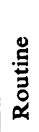 & 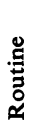 & 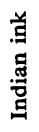 & $\bar{\sigma}$ & $\begin{array}{l}\text { : } \\
\text { : } \\
\text { : }\end{array}$ & $\sum_{\mu i}$ & $\sum_{\dot{\mu}}$ & $\sum_{i}$ & $\sum_{\omega \dot{j}}$ & $\sum_{\Psi}$ \\
\hline 产 & 1 & 1 & 1 & 잉 & 1 & 1 & 1 & 1 & 1 & 1 & $N$ & $a$ & 1 & 을 & 1 & 1 & 产 & 1 \\
\hline
\end{tabular}

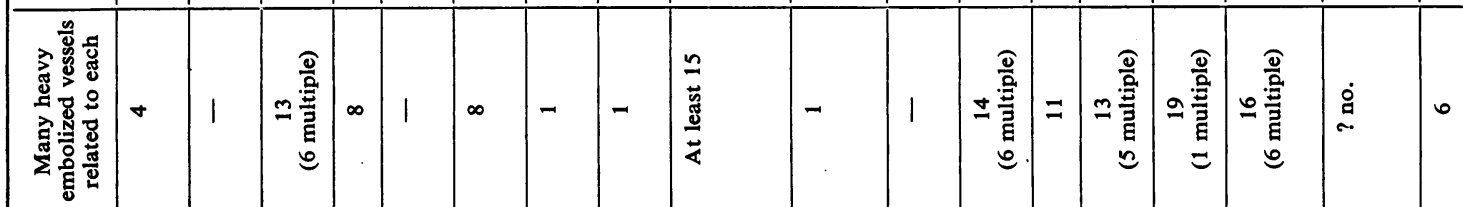

\begin{tabular}{|l|l|l|l|l|l|l|l|l|l|l|l|l|l|l|l|l|l|l}
\hline$m$ & 4 & 4 & $\infty$ & 4 & 1 & $m$ & - & - & + & - & 1 & $n$ & - & 6 & 0 & 4 & 4 & $n$ \\
\hline
\end{tabular}

\begin{tabular}{|c|c|c|c|c|c|c|c|c|c|c|c|c|c|c|c|c|c|}
\hline & & & & & & & & & & & & & & & & & \\
\hline 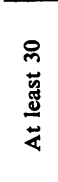 & n & 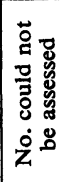 & 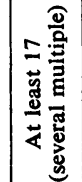 & $m$ & 1 & \pm & - & N & 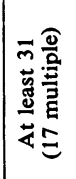 & - & 娣 & 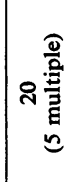 & $\stackrel{\infty}{\infty}$ & 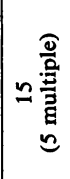 & 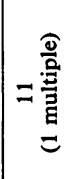 & & 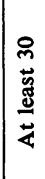 \\
\hline
\end{tabular}

\begin{tabular}{|c|c|c|c|c|c|c|c|c|c|c|c|c|c|c|c|c|c|c|}
\hline $1 \underset{r}{0}$ & 1 & ì & 1 & 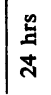 & 1 & 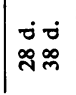 & I & 1 & 1 & 1 & $\begin{array}{l}\dot{j} \\
\dot{m}\end{array}$ & 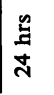 & 1 & $I_{\dot{J}}^{\dot{0}}$ & 1 & 1 & 站 & $\left.\dot{N}\right|_{m} ^{\dot{m}}$ \\
\hline 总的 & 1 & j & 1 & 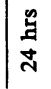 & 1 & 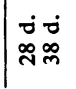 & 1 & 1 & 1 & 1 & 它 & 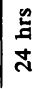 & I & $\dot{\dot{I}} \dot{+}$ & 1 & 1 & 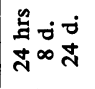 & 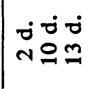 \\
\hline
\end{tabular}

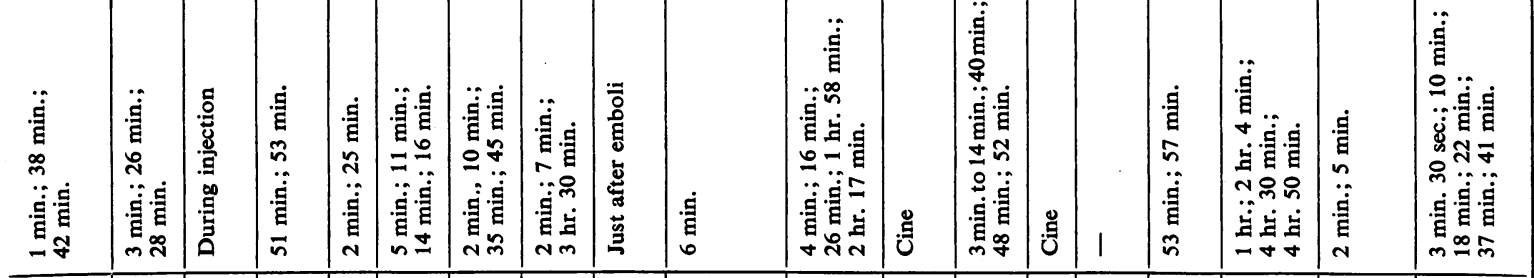

\begin{tabular}{|c|c|c|c|c|c|c|c|c|c|c|c|c|c|c|c|c|c|c|}
\hline 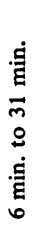 & 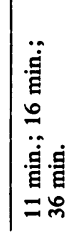 & 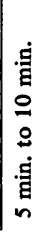 & 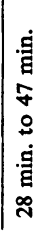 & 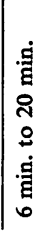 & $\begin{array}{l}\text { ğ } \\
\text { ż }\end{array}$ & 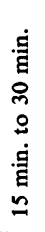 & 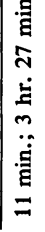 & $\begin{array}{l}\text { 音 } \\
0 \\
0 \\
0 \\
0 \\
. \dot{g} \\
=\end{array}$ & 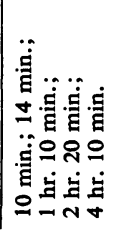 & 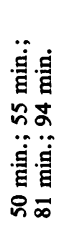 & $\begin{array}{l}\text { I: } \\
\text { ż }\end{array}$ & 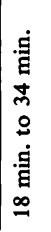 & 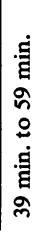 & 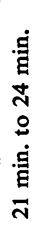 & 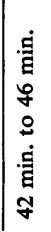 & 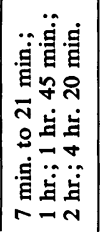 & 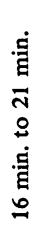 & 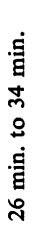 \\
\hline دـ & $\approx$ & A & $\alpha$ & د & $\approx$ & $\Delta$ & ــ & $\approx$ & $\propto$ & دـ & دـ & A & هـ & دـ & A & دـ & ــ & H \\
\hline & $\mathcal{F}$ & & $y$ & 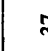 & i & $\bar{m}$ & & 요 & D & $\tilde{m}$ & q & in & $\tilde{m}$ & $\approx$ & $F$ & $\approx$ & ช & 1 \\
\hline & i & & & 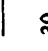 & $?$ & $\mid \vec{m}$ & & ల్ల & $1 \infty$ & J & 㒸 & $\approx m$ & I & o & $\mid=$ & I & F & $f$ \\
\hline
\end{tabular}


branching pattern, with single artery and vein accompanying each other, is similar to that of man. The colour of the fundus is pink, but of a less strongly reddish tint than the normal Caucasian human retina. The amount of pigment in the choroid varies in different animals and in some there is very little, so that the choroidal vessels can be seen clearly. There is no area which resembles the macula of the human eye.

No fundus abnormalities were visible in any of the animals on the colour photographs or control fluorescence angiograms which were taken before emboli were injected.

\section{Immediate Consequences of Embolization}

The emboli were visible in the retinal blood vessels within 2-3 seconds after their injection into the carotid artery. Sometimes they could only be seen as a sparkling dot rushing swiftly down the centre of a large vessel and vanishing into the periphery, but on other occasions they lodged in smaller central branches and almost at once came to rest. Stationary emboli appeared to distend the wall of the small artery in which they lodged and were visible as a bright dot breaking the normal contour of the vessel (Plate 1).

Sometimes emboli lodged in the mouth of small branch arterioles with most of their surface still within the main channel from which the branch arose. Under these circumstances the emboli sometimes became dislodged back into the main artery at a variable time interval after they first stopped. This gave a unique opportunity to study the responses of the vascular bed when flow was suddenly restored after a period of obstruction. On three occasions glass spheres came to rest for a short period of time in large arterioles without apparently being lodged in a branch or causing any obstruction to flow. It is not clear why this happened, but on each occasion the embolus subsequently moved into a more peripheral position and became wedged in a vessel.

Immediately after the embolus lodged in a branch arteriole the retina downstream appeared quite normal. However, there was always a striking change in the blood column distal to the embolus. It often broke into segments (Plate 42) and was usually much darker in colour than the blood in the normal arteriole. Sometimes the blood appeared even darker than that in an accompanying vein. The blood column was rarely stationary and frequently small packets of red cells could be seen moving slowly backwards along the arteriole towards the embolus.

\section{Early Changes (0-6 hours)}

Three to sixty minutes following embolization further changes took place in the area downstream to the embolus in about 80 per cent. of the embolized areas. The most striking change was an alteration in the colour of the retina. This varied from a barely perceptible gelatinous grey superimposed upon the normal soft pink colour of the pig fundus to a prominent greyish-white discoloration of the retina downstream to the embolus (Plates 1, 22, 42).

The greyish-white discoloration of the retina was reversible for, in several instances, emboli moved to more distal positions and thereby restored the flow to part of the 
white area; the discoloration disappeared in a few minutes. Further evidence that this colour change depended upon the degree of ischaemia was obtained from observations made when the eye was accidentally exposed to traction. Pulling on the eye reduced the retinal blood flow. When this occurred there was often a rapid increase in the whiteness of the area downstream to the emboli, which then tended to regress again when manipulation ceased.

\section{Late Changes (24 hours to 6 weeks)}

When the eyes were re-examined between 1 and 4 days after embolization, white patches which closely resembled the cotton-wool spots of humans were frequently seen in areas downstream to emboli (Plates 4, 12, 23, 43). Altogether 33 lesions of this kind were photographed and a number of others were noted to be present on ophthalmoscopic examination, although the animal was not photographed at this stage. By 7 days after embolization the cotton-wool spots had largely faded, leaving only a granular whitish-brown appearance in the affected area of the retina. Some granularity was still present after 14 days (Plates 13, 16, 17, 24), but later studies at 4 to 6 weeks showed that the appearance of the retina was almost normal apart from a few minute visible collateral vessels in some eyes. In one study, after the cottonwool spot cleared the retina was of a darker colour and it appeared that the nerve fibres had atrophied. Haemorrhages were seen in the vicinity of emboli on three occasions at intervals varying between 1 and 4 days after embolization (Plate 8). These eyes were not followed for a longer period and haemorrhages did not appear in other eyes studied for up to six weeks. There was no evidence of haemorrhage around the periphery of the cotton-wool spot as is often seen in the human eye.

The retinal arterioles in the vicinity of emboli were carefully examined for evidence of abnormalities of the wall or intravascular thrombosis. In some instances the arteriole immediately proximal to the embolus was abnormal. The blood column was either reduced in size or completely absent for a distance varying between 0.05 $\mathrm{mm}$. and $1 \mathrm{~mm}$. proximal to the glass sphere (Plate 25). This appearance sometimes persisted for several days. However, no evidence was obtained that there had been thrombosis of the blood column or aggregation of platelets within the vessel and no perivascular sheathing or inflammatory change was visible. Three arterioles studied between 3 and 7 days after embolization showed a general narrowing of the arteriole leading up to the embolus with a reddish-brown discoloration of the wall. These vessels were patent on fluorescence angiograms.

Examination of the arterioles at 2 to 6 weeks after embolization revealed few abnormalities. The glass spheres were still present but often they had moved slowly into much more distal positions in the vascular tree. Small collateral channels were sometimes visible on the colour photographs although these were never a prominent feature. In several examples the glass sphere apparently lay free in the retina but it was not clear whether this appearance was a true one or whether the sphere was still surrounded by a very thin vessel wall.

Changes in the appearance of the veins in embolized areas often occurred. When this area was large the vein draining the region often showed granularity or fragmentation of the blood column, indicating a sluggish flow. The diameters of veins draining areas of embolization were often reduced compared with control pictures. 


\section{Angiographic Studies}

\section{Immediate Circulatory Changes following Embolization}

After injection of emboli it was usually two or three minutes before an angiogram could be performed to study collateral flow in the embolized area. To study the immediate changes a different technique was necessary. On six occasions the emboli were injected suspended in 0.5 per cent. sodium fluorescein solution. The retinal camera was set up over the upper part of the nasal retina. Four studies were completed successfully using still photography and one using $16-\mathrm{mm}$. cine angiography.

Emboli were visible during the injection as small breaks in the fluorescent blood column in the arterioles (Plate 30). When the injection stopped the dye was rapidly washed out of the normal areas of the retina by undyed blood. The embolized areas showed up because the dyed blood persisted (Plate 31). Over the succeeding 20-30 seconds the dye was slowly removed from the territory of the blocked arteriole. These experiments were designed to provide evidence for or against the hypothesis that vascular closure might occur in arterioles retaining active tone after the perfusion pressure had fallen to a very low value immediately following embolization. If closure of the arteriolar lumen had taken place the effect would be to squeeze the dye in these vessels into the capillary bed. The exact opposite was observed, as the peripheral capillary bed was the first to empty, followed later by the main branches of the arteriole back to the embolus.

\section{Capillary Collateral Flow}

Angiograms of areas containing more than a hundred emboli which had been studied within thirty minutes of embolization were examined for evidence of collateral filling. Collateral filling of vessels in the territory of the blocked arteriole was observed in every instance, but the amount varied with the size and position of the lesion, and with other factors such as the level of the systemic blood pressure.

Flow within the embolized arteriole was halted by the embolus and the vascular bed downstream did not fill simultaneously with other areas. When the capillary bed of the surrounding normal retina was filled with dye the ischaemic area appeared entirely unperfused and non-fluorescent (Plates 2, 26, 28, 32, 34). In the succeeding few seconds fine capillary twigs could be seen slowly filling in from the periphery of the ischaemic area (Plate 34), first into minute arterioles and then back into the main stem of the blocked vessel. As the dyed blood emptied from the normally perfused capillaries a rim of sluggishly perfused capillaries around the edge of the ischaemic zone was seen still containing dye. Collateral flow back into the larger branches of the blocked arteriole took place from this zone of sluggishly perfused capillaries (Plates 29, 35, 47). These capillaries did not appear abnormally dilated and no channels of larger diameter appeared at this stage.

The dyed blood from capillary collaterals passed down the main division of the blocked arteriole and out again into smaller proximal branches, through the capillary bed, into branch veins draining the ischaemic zone. As a result, the direction of flow within part of the main division of the embolized vessel was often in the reverse 
direction to normal. The capillaries in the centre of the lesion filled late from the main trunk of the blocked arteriole. The number of capillaries filling in this area was less than in the surrounding normal areas and comparison with control angiograms of the embolized area confirmed that some capillaries were not perfused. Capillary perfusion was more effective near the periphery of the lesion and less so at its centre, even when all the main divisions of the vessel filled with dye from collaterals.

Factors influencing Capillary Collateral Flow.-The influence of changes in systemic blood pressure or the pressure gradient in the vessels within the eye was not examined in detail in this study. Comparative measurements of collateral blood flow were made in the different blocked arterioles within the same eye under comparable conditions.

\section{Size of Embolized Vessel}

Inspection of the fluorescence angiographic data revealed, as expected, that collateral in-filling of the ischaemic vascular bed was more effective when the area involved was small. The velocity of collateral flow was meașured in both large and small ischaemic lesions to test the hypothesis that the ratio of circumference to area was the main controlling factor in capillary collateral flow.

Single embolized arterioles with a diameter in the range $40-70 \mu$ in the nasal retina usually filled from the periphery at a rate of between 0.05 and $0.6 \mathrm{~mm}$. per second, but most values were in the range of $0 \cdot 1-0 \cdot 2 \mathrm{~mm}$. The rate of in-filling was slower when many adjacent arterioles had been embolized simultaneously. In several examples where a number of arterioles feeding a particular area had been blocked, capillary collateral flow was slow and the central part of the lesion was never perfused. Rates of collateral flow of less than $0.05 \mathrm{~mm}$. per second were recorded in such instances (Plates 32, 33).

When major vessels, above $80 \mu$ diameter, were blocked the area of retinal ischaemia was much larger and involved an entire retinal sector out to the ora. For obvious reasons this precluded good collateral flow as the lesion was large and capillary collaterals cannot exist at the retinal periphery. Only three such lesions were observed and although there was some in-filling by capillary collaterals at the central edges retrograde filling of the main trunk of the arteriole did not occur.

\section{Site of the Lesion}

Comparison of capillary collateral flow between different animals was difficult because the eyes were often heavily embolized, and it was impossible to judge the influence on pressure gradients of emboli in nearby vessels. When the eyes were only moderately embolized it was possible to study collateral flow in a number of individual vessels blocked by a single embolus at different sites in the retina. The velocity of collateral flow was different when emboli blocked arterioles near the disc compared with those further out in the nasal retina (Plates 26-29). Ischaemic areas only 1-2 $\mathrm{mm}$. in diameter near the optic disc sometimes had poor collateral flow in pictures taken up to 20 seconds after dye injection. Areas as small as this in the nasal retina usually filled rapidly through capillary collaterals. As there was unlikely 
to be any great difference in the perfusion pressure available in different parts of the same retina it is likely that the micro-anatomy of the capillary bed was responsible for the observed differences in collateral flow.

\section{Early Changes in Collateral Flow (0-6 Hours)}

Studies of collateral blood flow in the first few hours following embolization were often disturbed by distal movement of emboli which re-opened a substantial branch of the arteriole and restored blood supply to a part of the ischaemic area. As a result, the vascular watershed contributing collateral flow was altered and could not be compared with earlier observations. On two occasions emboli resting in the mouths of small arteriolar branches were dislodged into the mainstream of the arteriole after they had caused between 3 and 4 hours of ischaemia. When blood supply was restored by distal movement or dislodgement of emboli between 30 minutes and 4 hours after they first arrived, the vascular bed downstream appeared quite normal. No leakage occurred from these vessels when the blood flow was resumed.

Areas with an embolus in a stable position which were studied repeatedly during the first four hours after embolization did not show any systematic change in collateral flow during this period. Small increases and small decreases of collateral flow were observed but these might have been the result of extraneous factors such as the tendency of the animal to deteriorate during prolonged anaesthesia. There was no change in the capillary collateral flow pattern or appearance of larger collateral channels during the first few hours after embolization.

\section{Late Changes in Collateral Flow (24 Hours to 6 Weeks)}

The most striking late change which influenced the collateral blood flow pattern was the development of larger-diameter channels linking the obstructed segment of arteriole with surrounding normal arterioles. No evidence could be obtained for the presence of these channels at 24 and 48 hours and their presence could not be proved at 72 hours. One study performed at 4 days showed conclusively that larger diameter collaterals were present (Plate 9) and all studies made at longer than 4 days after embolization showed such channels which increased in both size and efficacy as time passed (Plates 36-41, 49-51).

\section{Position of Larger Collaterals}

Three types of larger-diameter collaterals could be distinguished. The first type arose by dilatation of capillary bridges at the arteriolar end of the capillary network, when a side branch of the blocked arteriole ran parallel to a side branch of the same arteriole immediately before the block. Dilatation of these capillaries produced a larger-diameter collateral with a relatively short path length linking the proximal and distal parts of the blocked arteriole (Plates 36-39, 49-51). The second type also arose by dilatation of capillaries at the arteriolar end of the circulation. These capillaries lay at the peripheral margin of the ischaemic zone and linked the blocked segment of the arteriole with more distant surrounding normal vessels (Plates 40, 41). The larger-diameter channels which resulted were much longer than those which linked adjacent parallel branches of the blocked arteriole itself. The third type of 
channel was not really a collateral but appeared as a by-passing of the embolus within the lumen of the blocked arteriole. The process responsible could not be defined, but a number of by-passed emboli of this kind were seen in eyes which had been embolized for between 2 and 6 weeks (Plates 18, 19).

The development of larger-diameter collateral channels brought about a substantial increase in the rate of in-filling of ischaemic areas as observed by fluorescence angiography. Instead of the slow filling from the periphery observed in acute studies of capillary collateral flow a larger diameter collateral brought about more rapid filling of the main trunk of the distal part. At first this was only partly effective and some areas of the periphery of the lesion were still fed by capillary collaterals (Plates 36, 37). Between 1 and 2 weeks after embolization the rapidity of collateral flow was much increased by the presence of these larger-diameter collateral channels, but perfusion of the area beyond the block was still delayed when compared with surrounding normal areas of retina. Filling of the capillary bed in the central part of large ischaemic lesions was also incomplete. The number of larger-diameter collaterals visible varied from 1 in some small areas of ischaemia to as many as 5 or 6 in larger areas (Plates 40, 41).

The efficiency of collateral blood flow continued to increase up to 6 weeks after embolization. By 6 weeks, a combination of the distal movement of emboli and development of large-diameter collaterals was so effective that there was little visible delay in the capillary perfusion of embolized territories (Plates 18, 40). Capillary filling appeared to be complete. At this stage, the compensatory mechanisms had resulted in nearly complete restoration of blood flow even in multi-embolized areas.

No capillary aneurysms were present at the periphery of the ischaemic areas or on dilating collaterals at any stage.

\section{Vascular Leakage}

Vessels in ischaemic areas did not leak fluorescein dye into the retina even when flow was suddenly restored by dislodgement of an embolus. No leakage or vascular abnormality was seen around the border of cotton-wool spots. Only 3 out of the 33 cotton-wool spots observed became fluorescent, and these did so only faintly. However, profuse leakage of dye was observed in the vicinity of nearly 40 per cent. of all emboli on the first study. Leakage often arose from a small length of the arteriole immediately proximal to the embolus and spread over an area up to $0.5 \mathrm{~mm}$. in diameter over the succeeding 10-15 seconds (Plates 28, 29, 33, 35). On several occasions an embolus was observed to lodge at one point in an arteriole and then move slowly to a more distal position over a period of minutes or hours. Conspicuous leakage of fluorescein usually took place along the length of arteriole traversed by the slowly moving embolus. Strong evidence was obtained that this leakage was related to trauma to the vascular wall and electron-microscopic observations in some of these cases indicated damage to the wall and stripping of endothelial cells (Plates 10, 11). Although leakage of fluorescein from arterioles was common, haemorrhage was rare. Ophthalmoscopic examination of arterioles which leaked fluorescein did not reveal any abnormality in such areas before the dye was injected. Nor was there any evidence of oedema in the surrounding retina. Careful examination of the capillary perfusion on fluorescence angiograms did not show any evidence 
of impaired blood flow in the capillary bed immediately adjacent to arterioles which leaked dye (Plates 28, 29). In the pig the larger arterioles have a more superficial position in the retina than those in man. However, it does not appear that leakage from the arteriole was sufficient to disturb the pressure relations in the capillary bed in these experimental studies.

Leakage of dye was most conspicuous in studies performed in the first few hours after embolization. However, some leakage was evident around emboli injected up to 4 days previously (Plate 9). None was observed at longer intervals. No leakage was observed on control angiograms before injection of emboli nor in areas remote from emboli. Collateral vessels did not leak fluorescein.

\section{Injection Studies}

Indian ink injected preparations of retinal vessels are sometimes unsuccessful as there may be scattered areas of incomplete filling. Sodium nitrite irrigation and injection at physiological pressure minimized this difficulty and we obtained some satisfactory specimens.

The Indian ink injected retinae of embolized pigs were useful for demonstrating the alterations in the vascular bed following embolization. Study of preparations made several hours after embolization showed the capillary collaterals filling in the distal segment of an occluded arteriole, thus corroborating the in vivo fluorescein studies (Plates 46-48). Larger collaterals arising from the pre-existing capillary bed, and linking either adjacent vessels or the proximal and distal segments of a blocked vessel, were noted in a specimen prepared 5 weeks after embolization, and again this confirmed ophthalmoscopic and fluorescein observations (Plates 49-51). These larger collaterals were always arterio-arteriolar in nature, and arterio-venous anastomoses were never seen. In addition, Indian ink preparations were useful in studying the vascular bed underlying cotton-wool spots, and in a number of instances there was poor filling of the superficial radial peri-papillary capillaries in the area of the lesion even though deeper retinal capillaries were better filled.

\section{Correlation of Clinical and Angiographic Findings in the Embolized Retina}

Angiographic studies performed as early as 2 minutes after embolization indicated that the downstream capillary bed was poorly perfused and that its blood flow was drawn from the surrounding capillary bed through capillary collaterals. At this stage no change in the colour of the retina in the ischaemic area was noted with the ophthalmoscope or on subsequent scrutiny of colour photographs. Later greyishwhite discoloration developed in many of the embolized areas and the margin of the area was accurately delineated by the zone of poor capillary perfusion seen on the fluorescence angiograms (Plates 1-3). There was fairly good correlation between the amount of capillary collateral flow and the presence or absence of greyish-white areas in the retina. Discoloration of the retina was much more likely to appear when collateral flow was poor. Areas near the optic disc were more prone to develop this change than those further away. However, some areas with poor collateral flow did not become noticeably discoloured and others with relatively good collateral flow 
did develop the greyish-white appearance. This difference cannot be satisfactorily explained from the data available. Distal movement or dislodgement of emboli which restored flow resulted in disappearance of the greyish-white colour within 10 to 20 minutes.

During the next 24 hours some of these areas returned to a normal appearance and others developed into a typical cotton-wool spot with a shiny white appearance and frayed irregular edges. The areas most likely to develop cotton-wool spots were those near the optic disc which had poor collateral flow in the early stages following embolization. Although this statement was generally correct there were one or two exceptions. These may be explained by variations in the general condition and particularly the systemic blood pressure, of the animal in the first 12 hours following anaesthesia, which were not accurately known. These changes may affect collateral flow and thereby influence the tendency to form cotton-wool spots. Secondly, there may be individual variations in the susceptibility of nerve fibres to ischaemia. Distal movement of emboli after the acute study, but before the second, 24 or 48 hours later, sometimes restored flow to all or part of an ischaemic area after an unknown period. In several instances such restoration of flow did not prevent the formation of a cotton-wool spot in the territory of the arteriole (Plates 23, 43-45). Analysis of the available photographs suggests that distal movement of emboli at some time between 3 and 20 hours after embolization may restore flow but not prevent irreversible damage culminating in the formation of a cotton-wool spot.

Blot-haemorrhages appeared on three occasions. All of them were found in a multi-embolized area of retina where profuse leakage of fluorescein from arterioles was also observed. As the haemorrhage was a large superficial pool of blood, covering the vessels, examination of the colour and fluorescence photographs did not permit any conclusion about its point of origin. In one of the three areas of haemorrhage a glass sphere was noted to be apparently free within the retina. The wall of an arteriole may have ruptured at this point, releasing both the embolus and the blood.

Return of the retina to a normal appearance in areas of cotton-wool spots roughly paralleled the restoration of blood flow by collaterals. However, restoration of flow was not an important factor in the disappearance of cotton-wool spots as these followed a normal life cycle in areas where flow was restored before 24 hours. By 4-6 weeks after embolization both fluorescence angiograms and colour pictures appeared almost normal, apart from the presence of the glass microspheres in the retina. It was often necessary to consult the colour photographs to identify the position of the emboli on the fluorescence angiograms. Only a few of the larger collaterals were visible in the colour photographs. Those observed in the pig were not so prominent as some seen in the cat (Ashton and Henkind, 1965).

It was possible to correlate the clinical and pathological findings in this study with definite alterations in the vascular bed of the retina induced by embolization. The finding of capillary collaterals which function immediately after arteriolar occlusion confirmed our impression that the capillary bed of the retina is an extended branching network with multiple arteriolar feed-points (excepting of course, the radial peripapillary capillaries which possess few anastomoses and thus are at a disadvantage in arteriolar occlusion). The larger arteriolar collaterals which appeared at a later stage developed from the pre-existing capillary bed. As attempts at retinal digestion 
were unsuccessful in pigs, we were unable to demonstrate that these channels acquired the morphologic characteristics of larger calibre vessels, as they do in the cat (Ashton and Henkind, 1965).

Cotton-wool spots in the pig developed exclusively at sites of arteriolar occlusion where the capillary collateral flow was poor, and were particularly liable to develop when multiple emboli had blocked adjacent arterioles and reduced capillary collateral flow. Light and electron-microscopical examination showed that the pig cottonwool spots consist of an intracellular swelling of axons in the nerve fibre layer of the retina (Plates 7, 11, 14, 15, 20, 21). Despite swelling of retinal elements, good capillary perfusion was present within the substance of many cotton-wool spots, although the number of capillaries filling appeared less than in normal areas (Plates 6, 44, 45).

Leakage of fluorescein into the retina, implying leakage of protein to which the former is bound, or retinal haemorrhage, occurred only in those instances where the glass emboli had injured the endothelium of the arteriole, and this was demonstrated by electron microscopy as a partial absence of endothelium lining the vessel.

All the techniques brought to bear on the various facets of this project had value, and together they complemented each other. For example, the changes in microvascular anatomy visible on the fluorescence photographs were amply confirmed by studying Indian ink preparations under higher power and with greater resolution.

\section{DISCUSSION}

The discussion will be divided into two main parts: (1) circulatory dynamics; and (2) cotton-wool spots.

\section{Circulatory Dynamics}

\section{Vascular Micro-anatomy}

The retinae of man and of a variety of animals including monkeys, cats, and pigs, derive their nutrition from two separate vascular supplies: $(a)$ from the choriocapillaris which nourishes the pigment epithelium and the outer layers of the retina; and $(b)$ from the retinal vessels which lie in and supply the inner half of the retina. We are concerned with the latter only.

The vascular tree of the retina is essentially a branching network of small-calibre vessels with an interposed and highly developed capillary bed, which is supplied by numerous arteriolar feed-points and drained by many venules. At the disc (in man) there are minor communications between the retinal and choroidal arterial supply; otherwise the retinal vessels do not normally communicate with the vessels of adjacent structures, or with one another. For this reason, the retina is considered to have an "end-artery" blood supply.

The capillaries of the retina are arranged in a rich inter-communicating meshwork which occupies several levels down to and including the inner nuclear layer. The network tends to be denser in the external layers and more open in the superficial retina (Michaelson, 1954). A well-defined plexus of radially arranged capillaries is 
present in the superficial nerve-fibre layer around the disc in man, monkey, cat, and pig (Michaelson, 1954; Henkind, 1966).

At the disc the arteries are histologically similar to small size systemic arteries and contain a well-developed muscularis and internal elastic lamina, but soon after their first or second bifurcation the elastic and muscular coats are greatly reduced and the term "arteriole" then becomes applicable. Retinal capillaries are endothelial tubes containing in their walls two distinct cellular elements: the endothelial cells lining the basement membrane, and the intramural pericytes within the basement membrane. The structure is similar to that of other capillaries in the body, particularly to those of the brain (Ashton and Oliveira, 1966).

At present there is no definite evidence of a vasomotor supply to the retinal vessels (Malmfors, 1965). However, the calibre of the larger retinal vessels is certainly modified by physical and chemical stimuli, such as changes in the oxygen tension of arterial blood, or infusion of vasopressor substances (Sieker and Hickam, 1953; Dollery, Hill, and Hodge, 1963; Dollery, Hill, Mailer, and Ramalho, 1964).

\section{Pressure-Flow Relations in the Normal Eye}

Before discussing the haemodynamic consequences of embolization it is necessary to consider briefly the pressure-flow relations in the normal eye. The pressure driving blood through the eye is the arterial pressure $(\mathrm{Pa})$ minus the intra-ocular pressure (Poc). As the downstream venous pressure outside the eye (Pv) is lower than Poc it has no effect on pressure or flow in the eye. The venous pressure inside the globe must exceed Poc for flow to continue so that there is a zone of rapid change of pressure in the veins at the outflow from the eye. This situation has been named a "vascular waterfall" or "sluice", as the pressure and flow are unaffected by downstream pressure changes so long as the downstream pressure is less than Poc. The haemodynamic consequences of this situation have been reviewed by Permutt and Riley (1963). Flow through the capillary bed may be regulated in part by the intramural pericytes, but this role has not yet been proved. The regulation of arteriolar resistance depends upon smooth muscle tone. Active tone not only determines resistance to flow but can enable an arteriole to shut off flow before the perfusion pressure reaches zero. The level of arterial pressure when flow ceases is referred to as the "critical closing pressure" (Burton, 1962). Serial fluorescence angiogram studies in the normal pig eye show that flow through the retinal capillary bed is continuous. The capillary bed itself is an extended branching network with many feeding arterioles and draining venules and it does not, as suggested by Toussaint, Kuwabara, and Cogan (1961), resemble a glomerulus, which has single feeding and draining vessels.

\section{Immediate Consequences of Arteriolar Obstruction}

The retinal arterioles are end-arterioles in the sense that they have no major connexions with adjacent arterioles. When an arteriole is blocked by an embolus the flow is completely arrested and the downstream pressure starts to fall rapidly. If the vessels had no active tone and they were linked to the veins by a glomerular type 
of capillary bed, the pressure in the arteriole beyond the block would quickly reach the level of the tissue or venous pressure, whichever was higher. The presence of numerous intercapillary channels prevents complete cessation of flow. As the arteriolar pressure falls it approaches the pressure in capillaries of the surrounding retina at points where they are linked to the capillary bed of the blocked vessel. At this point flow reverses in the minute arteriolar branches feeding the capillary bed, as there is now a pressure gradient from the normal surrounding capillary bed through the capillary net, back into the blocked arteriole. Flow still proceeds in the normal direction through the capillary bed in the centre of the territory of the blocked arteriole, driven by the very low pressure provided by the capillary links at the periphery of the ischaemic zone (Fig. 3).

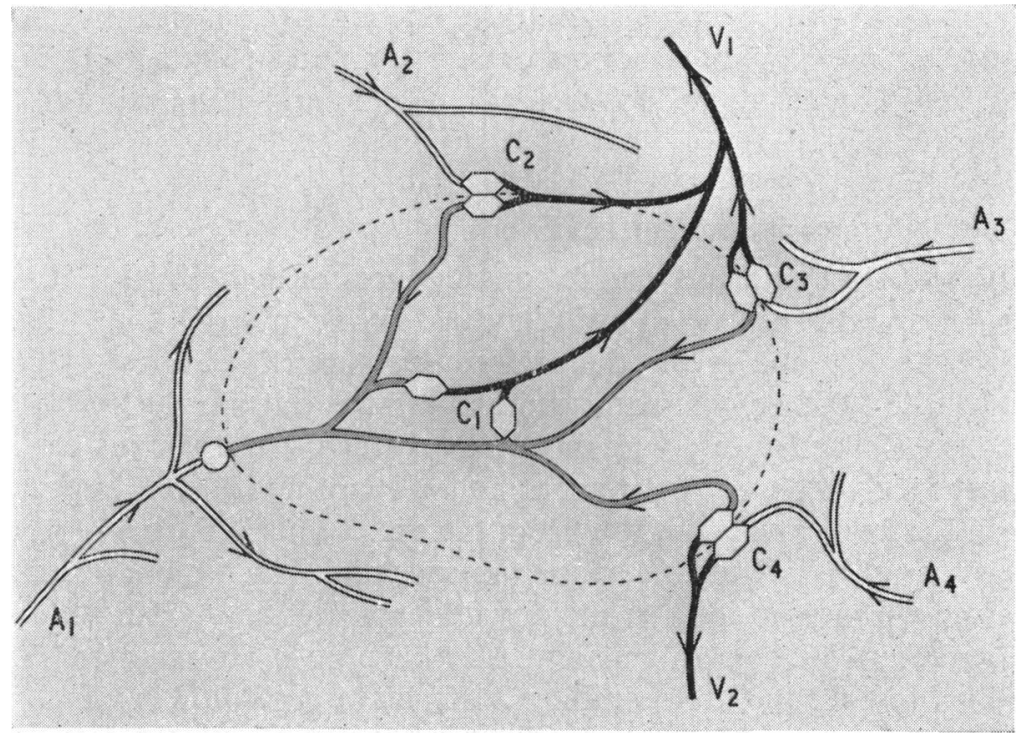

Frg. 3.-A schematic diagram of an embolized area. At the left is an arteriole $\left(A_{1}\right)$ blocked by a glass sphere (circle, lower left). The vascular watershed of the territory of the blocked arteriole is shown by the dotted line and the segments of the capillary network by hexagonal lozenges $\left(C_{1}-C_{4}\right)$. The grey lines represent branches of $A_{1}$ beyond the block filling retrogradely via capillary collaterals $\left(C_{2}, 3,4\right)$, fed by adjacent unblocked arterioles $\left(A_{2}, 3,4\right)$. Capillaries in the centre of the lesion $\left(C_{1}\right)$ are fed by the retrograde flow and drained into the vein $\left(V_{1}\right)$.

Topographical factors impose severe limitations on the effectiveness of capillary collateral flow. If the capillary bed is regarded as an extended regular branching network in a single layer, then the interface contributing collaterals is proportional to the circumference $2 \pi R$ and the tissue demand for oxygen to the area $\pi R^{2}$. Thus, the ratio of available flow to demand is $2 / R$. The larger the lesion the less effective capillary collateral flow can be, particularly in the centre of the zone of ischaemia. This analysis does not take into consideration any oxygen which may diffuse through from the choriocapillaris.

The results show that the rate of in-filling by collaterals was only $0.05-0.6 \mathrm{~mm}$. per second in arterioles wherein normal forward flow velocity was about $15-25 \mathrm{~mm}$. per second. Even these low values overstate the available supply of oxygen and other 
materials to the ischaemic region. Capillary collateral blood has already passed through capillaries at the edge of the lesion which have a sluggish flow and must, therefore, be surrounded by relatively hypoxic tissue. Thus, the blood filling the blocked arteriole is essentially of venous composition and this accounts for its dark colour.

Changes in micro-anatomy of the capillary bed, particularly variations in the number of capillary connexions near the high pressure end of the bed, will influenc? the available capillary collateral flow. Low velocities of collateral flow were observed on several occasions when small arterioles near the disc were blocked by small emboli. The explanation for this finding may be the relative sparsity of intercapillary links in the radial peri-papillary bed (Dollery and Henkind, 1966).

Active tone in arterioles and a "critical closing pressure" could theoretically lead to closure of arterioles downstream to emboli, if the driving pressure from capillary collaterals were less than the closing pressure. Fragmentation of the blood column was common in the distal part of the arteriole but closure was not observed. This suggests that tone in these sections of the embolized arteriole was low. Closure of segments of arteriole proximal to the embolus was observed on several occasions. This probably reflects spasm in the wall caused by trauma from the glass microsphere.

Incomplete perfusion of the capillary bed in the centre of ischaemic areas was observed both in acute and long-term studies. It is unlikely that this represents an active contractile process in the capillaries, and other explanations such as sludging of blood, swelling of endothelial cells, increase in tissue tension due to swelling of cells, or later capillary atrophy are more probable.

\section{Growth of Larger Collateral Channels}

Studies continued for up to 6 hours on the first day of embolization did not suggest that any larger-diameter collateral channels appeared. Increase in flow could usually be explained by distal movement of emboli. The first definite evidence of larger channels, in the pig, was obtained 4 days after embolization. These facts are very strong evidence against the presence of any pre-formed arteriolar bridges in the retinal micro-circulation, as these would presumably dilate soon after the flow was obstructed.

The factors which determine the growth of larger collaterals are of both theoretical and practical importance (Liebow, 1963). It is unlikely that changes in the pressure gradient play a direct role, as the available pressure head has to be distributed over two capillary beds. The fall in pressure in the blocked arteriole explains the initiation of capillary collateral flow but does not offer an explanation of the dilatation of some capillaries.

It is probable that the stimulus to capillary dilatation in some of the capillaries around the edge of the ischaemic territory is related to hypoxia or changes in cellular metabolism caused by it. Once capillary dilatation has been initiated the situation is potentially unstable. As the thin-walled tube dilates, the pressure within it will increase because of the larger-diameter connexion to the patent arteriole. As the transmural pressure rises in the capillary the tension in its wall increases. The shorter the path length through the capillary bed from patent to blocked arteriole, the smaller the pressure gradient in the vessel and the greater the transmural pressure 
at its downstream end. These factors will tend to bring about maximal dilatation of the shortest path from artery to vein but can only operate once an increase in capillary diameter has been initiated by other means.

This hypothesis does not yield any satisfactory explanation why larger-diameter channels from artery to vein do not occur, as similar factors would operate here. It appears that there must be some properties which are specific to the high-pressure end of the capillary bed.

A dilated capillary connecting a blocked arteriole to a patent arteriole must have a transmural pressure which is appropriate to an arteriole. It is not surprising that digest studies in the cat have demonstrated that these capillaries acquire a cellular coat and take on the morphology of an arteriole. If they did not, these thin-walled channels perfused at a high pressure might be expected to burst and cause haemorrhage. It is interesting to note that haemorrhage was rare and that none of these larger-diameter collateral channels developed aneurysms.

\section{Cotton-wool Spots}

Cotton-wool spots are an important feature in the diagnosis and prognosis of a variety of systemic disorders. Their pathogenesis and morphology have engendered much comment and speculation in the past (Friedenwald, 1949; Christensen, 1958), but recent studies have indicated that in humans these lesions are due to alterations in the underlying vascular bed with functional obliteration of the capillaries (Ashton, 1959; Ashton and Harry, 1963; Hodge and Dollery, 1964), and that they consist primarily of altered neurones (Wolter, 1959; Ashton and Harry, 1963). The present experiment led to the production of lesions which clinically resemble the cotton-wool spot in humans. These have been exhaustively studied and compared with their human counterpart. Similar lesions have been produced in the dog with latex emboli (Gay, Goldor, and Smith, 1964). It must be kept in mind, however, that while human cotton-wool spots have been mainly studied in hypertensive individuals they also can occur in conditions where vascular disease plays no obvious part.

The life cycle of the pig cotton-wool spot is short. A grey patch in the retina appears within a few minutes of embolization and the cotton-wool spot is fully developed within 24 to 48 hours. It then fades rapidly and almost all traces have disappeared within 7 to 14 days. In man the lesions follow a similar but much more prolonged life cycle. Many human cotton-wool spots begin as a small gelatinous white area, and spread rapidly over 2 or 3 days to become a fluffy white spot with frayed edges. During this stage of expansion the human cotton-wool spot may deflect large veins and arteries which return to their initial position as the lesion disappears in the following 6 to 12 weeks (Hodge and Dollery, 1964). Deflection of large retinal vessels by the experimental cotton-wool spot was not observed. The colour of the cotton-wool spot in the pig retina is very similar to that in man.

Most of the experimental cotton-wool spots were fairly large, ranging from 0.5 to $6 \mathrm{~mm}$. in diameter, and this, to some extent, reflects the size of emboli used and the arteriolar branches which they occluded. On the other hand, human cotton-wool spots are small, ranging from about 0.1 to $1.5 \mathrm{~mm}$. in diameter, but few exceed $0.8 \mathrm{~mm}$. in diameter. If the human lesions arise from arteriolar occlusion the vascular branches concerned must be small and probably less than $20 \mu$ in diameter. 
Fluorescence angiograms in hypertensive patients with cotton-wool spots often reveal points of leakage on small arterioles of this order of size. In some of the experimental studies a mixture of emboli was used that included some $15 \mu$ only in diameter. When these smaller emboli occluded a single branch arteriole, without embolization of adjacent arterioles, there was usually no formation of a cotton-wool spot. Presumably, in the pig, collateral flow via capillary channels is sufficient to preserve a small ischaemic area after its arteriole has been occluded and hence prevent formation of a cotton-wool spot.

In human hypertensive retinopathy there is a close topographical relationship between cotton-wool spots and haemorrhages which are often arranged around their circumference. The only haemorrhages that appeared in embolized retinae were three large blots and almost all the cotton-wool spots were entirely free of associated haemorrhage.

Fluorescence angiograms show some parallels but also some important differences from the human findings. The characteristic fluorescence angiographic features of cotton-wool spots in hypertension are circumferential micro-aneurysms, central capillary closure, and leakage of dye into the area of the cotton-wool spot. Often there are localized diffuse leaking points on or near feeding arterioles, not necessarily within the area enclosed by the white spot. No circumferential micro-aneurysms or fluorescein leakage occurred in any of the animal studies although these would have been easily visible if present. A faint diffuse fluorescence was observed in three cotton-wool spots in one animal but in none of the others. Poor capillary perfusion was always present in the territory within which the cotton-wool spot formed (Plate 5), and localized leaking points on arterioles often occurred in relationship to emboli, whether these caused cotton-wool spots or not. In both experimental and human cotton-wool spots the leaking points on arterioles were often outside the area of the white patch.

Thus the experimental lesions closely resemble the human cotton-wool spots in regard to colour, texture, poor central capillary perfusion, and arteriolar leaking points. They differ in that the human lesions are smaller, expansile, have a circumferential rim of capillary abnormalities, including aneurysms, and leak fluorescein profusely. These are substantial differences which raise some important questions concerning the aetiology of the human cotton-wool spot. An active leaking or exudative process is usually associated with the human lesion but not with the animal one. If occlusion of small arterioles leads to the formation of the cotton-wool spot why is the area not sustained by capillary collaterals as it is in the pig? Several explanations seem possible: (1) the difference in anatomy of the vascular bed in the two species may be greater than we imagine, and (2) there may be damage to surrounding arterioles so that more than one feeding arteriole is involved, as has been demonstrated in some instances by Ashton and Harry (1963). Hypertensive patients, even when the severe hypertension is of short duration, often have diseased retinal arterioles and this may affect the capacity of the capillary bed to produce collaterals. However, this does not explain the most striking difference, the leakage of fluorescein from vascular abnormalities at the edge of the human lesion. It is also a fact that hypertensive human retinae may show leaking points on arterioles feeding an area where a cotton-wool spot may later arise, but at this stage a failure of 
downstream capillary perfusion is not seen. The period of ischaemia necessary to produce a cotton-wool spot need only be of short duration. This was seen clearly in some of the experimental studies when the embolus had moved to a more distal position within 24 hours, but the whole of the initially poorly perfused area developed a cotton-wool spot. It appears, from the experimental data, that less than 24 hours of ischaemia are required to make the formation of a cotton-wool spot inevitable. If the leaking points in human arterioles represent regions of arteriolar necrosis, as is probable, then a transitory obstruction of arteriolar flow may occur from swelling of the wall or even localized clot formation. This may be reversible within a few hours and yet lead to formation of a cotton-wool spot. These arguments are speculative, but they suffice to show that the experimental induction of cotton-wool spots by arteriolar occlusion does not necessarily establish conclusively that precisely the same mechanism operates in severe hypertensive retinopathy.

The significance of the ultrastructural changes in cotton-wool spots will be discussed in Part II of this work.

\section{Acknowledgements}

We are grateful to our technical staff, Miss Carole Vincent, Mrs. Morag Engel, and Mr. L. Chennery, and the staff of the Experimental Surgical Unit, particularly Mr. J. Robson, Mr. M. Cussen, and Mr. D. Wilson, without whose help this work would not have been possible. We also thank Mrs. Gwen Cox for looking after the records and typing the paper.

This work was supported by grants from the Tobacco Research Council and the Medical Research Council.

\section{REFERENCES}

Ashton, N. (1959). Lancet, 2, 625. (1963). Brit. J. Ophthal., 47, 521.

and HARRY, J. (1963). Trans. ophthal. Soc. U.K., 83, 91.

- and Henkind, P. (1965). Brit. J. Ophthal., 49, 225.

and Oliveira, F. (1966). Ibid., 50, 119.

Burton, A. C. (1962). In "Handbook of Physiology", Section II: Circulation, Vol. 1, p. 85. American Physiological Society, Washington, D.C.

Christensen, L. (1958). Trans. Amer. ophthal. Soc., 56, 451.

Dollery, C. T., and Henkind, P. (1966). Invest. Ophthal., in the press. , Hill, D. W., and Hodge, J. V. (1963). J. Physiol. (Lond.), 165, 500.

,-- Mailer, C. M., and Ramalho, P. S. (1964). Lancet, 2, 291. , Hodge, J. V., and Engel, M. (1963). Med. biol. Illus., 13, 4.

—, Ramalho, P. S., Paterson, J. W., Hill, D. W., Henkind, P., Shakib, M., and Ashton, N. (1965). Lancet, 1, 1303.

FriedenWald, J. S. (1949). Amer. J. Ophthal., 32, 487.

GAY, A. J., Goldor, H., and SMITH, M. (1964). Invest. Ophthal., 3, 647.

GuINEY, E. J. (1965). Irish. J. med. Sci., 6th ser., no. 474, p. 273.

Henkind, P. (1966). Exp. Eye Res., 5, 10.

Hodge, J. V., and Dollery, C. T. (1964). Quart. J. Med., 33, 117.

Kuwabara, T., and Cogan, D. G. (1960). Arch. Ophthal. (Chicago), 64, 904.

Liebow, A. A. (1963). In "Handbook of Physiology", Section II: Circulation, Vol. 2, p. 1251. American Physiology Society, Washington, D.C.

Malmfors, T. (1965). Acta physiol. scand., 65, 259.

Michaelson, I. C. (1954). "Retinal Circulation in Man and Animals". Thomas, Springfield, Ill.

Permutt, S., and Riley, R. L. (1963). J. appl. Physiol., 18, 924.

SieKer, H. O., and Hickam, J. B. (1953). Circulation, 7, 79.

Toussaint, D., Kuwabara, T., and Cogan, D. G. (1961). Arch. Ophthal. (Chicago), 65, 575.

Wolter, J. R. (1959). Amer. J. Ophthal., 48, 473. 
Grey-white Patch at One Hour

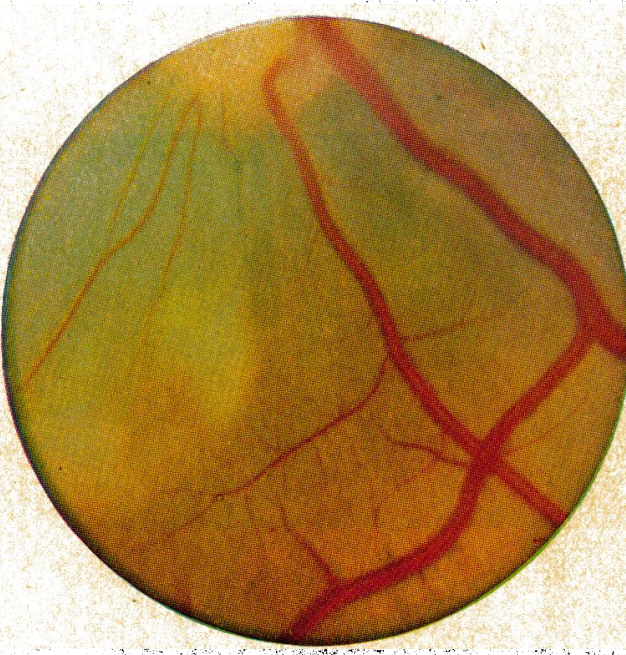

Plate 1.-Pig 41. Colour photograph taken 46 minutes after embolization showing two grevishwhite areas with striate edges, downstream to emboli.

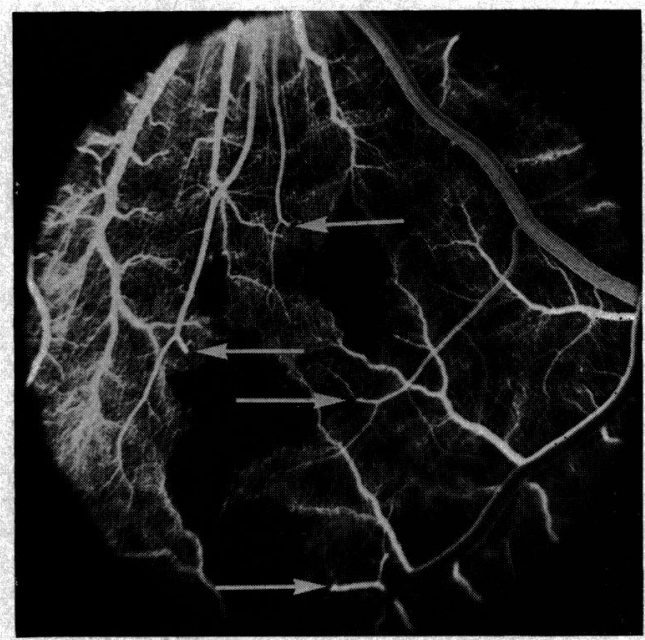

PLAt 2. I 4 41. Captlity phase fluorescence angiogram of the retina in Plate 1 (centred lower and to left). Several emboli are present (arrows) and poorly perfused dark areas of retina downstream to them correspond exactly with the greyishwhite regions.

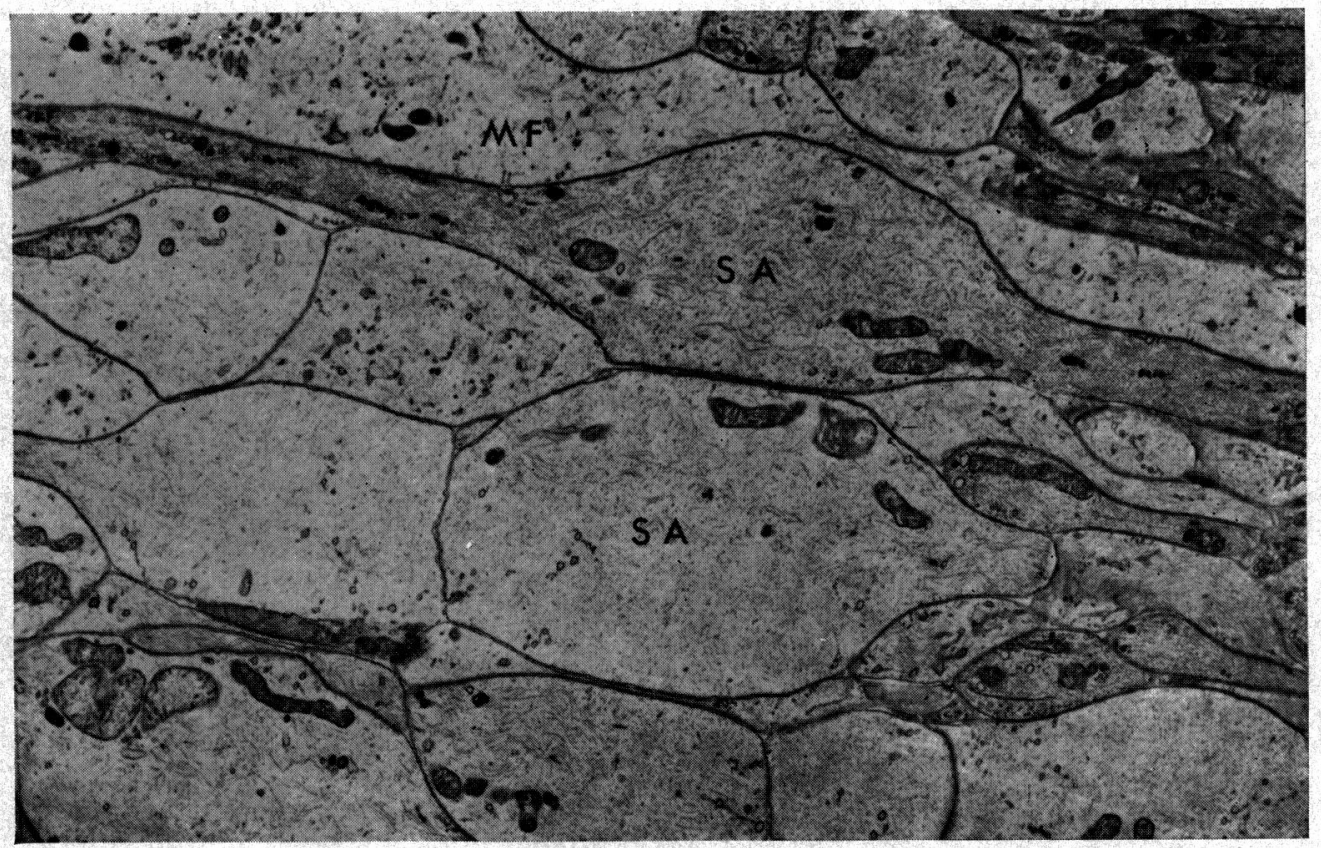

PLATE 3.-Pig 41. Eleotron micrograph thowiy, stoollen axons (sA) and Müler fibres (MF) in the nerve fibre layer, one hour after embolization. $\times 8,000$. 


\section{Cotton-wool Spot at 24 Hours}

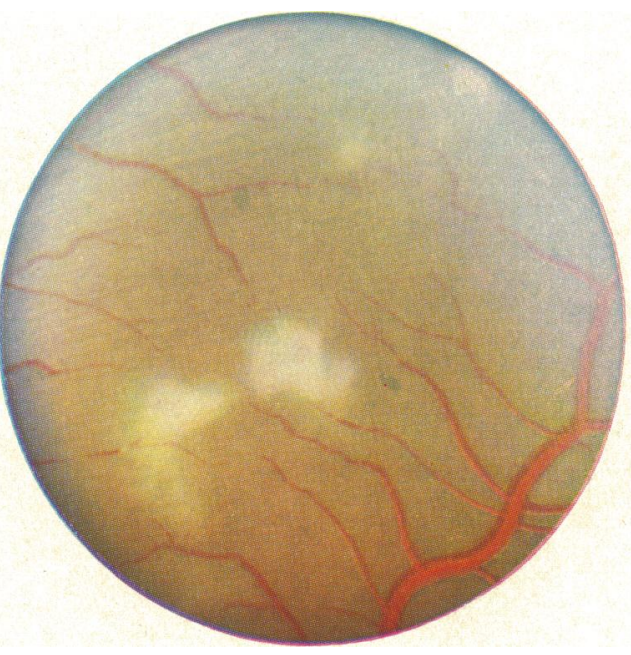

Plate 4.-Pig 30. Twenty-four hours after embolization showing typical white and fluffy cotton-wool spots with striate edges.

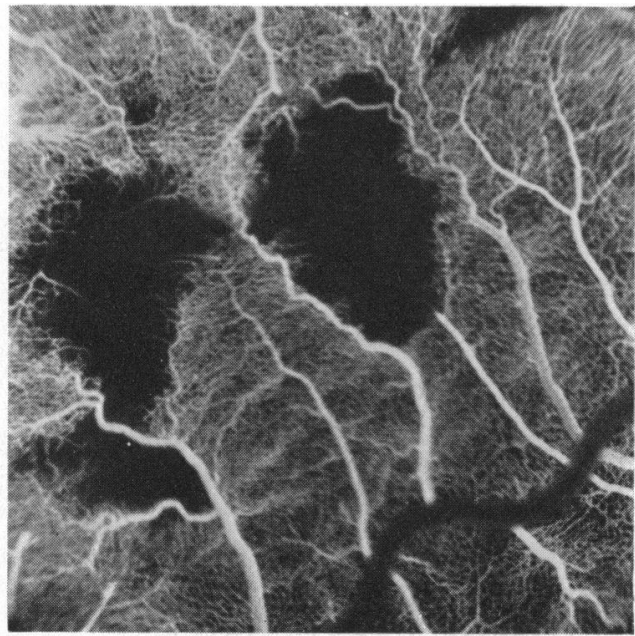

Plate 5.-Pig 30. Capillary phase (1.95 seconds) fluorescence angiogram showing a close-up of the two large cotton-wool spots, which appear dark and non-perfused.

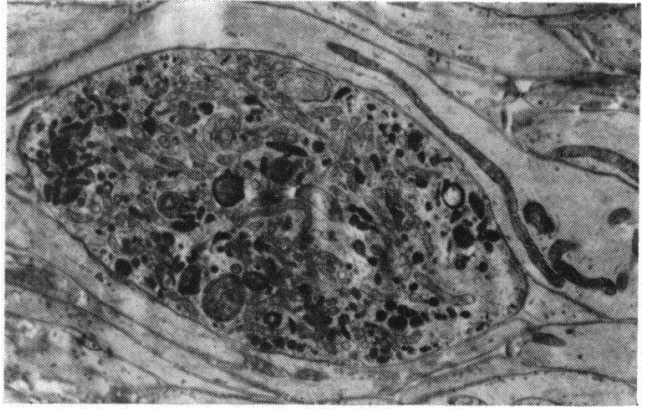

Plate 7.-Electron micrograph of a swollen hypertrophic axon (torpedo) in the nerve fibre layer, showing microvesicles, membranous whorls, numerous mitochondria, and dense bodies. $\times 6,000$.

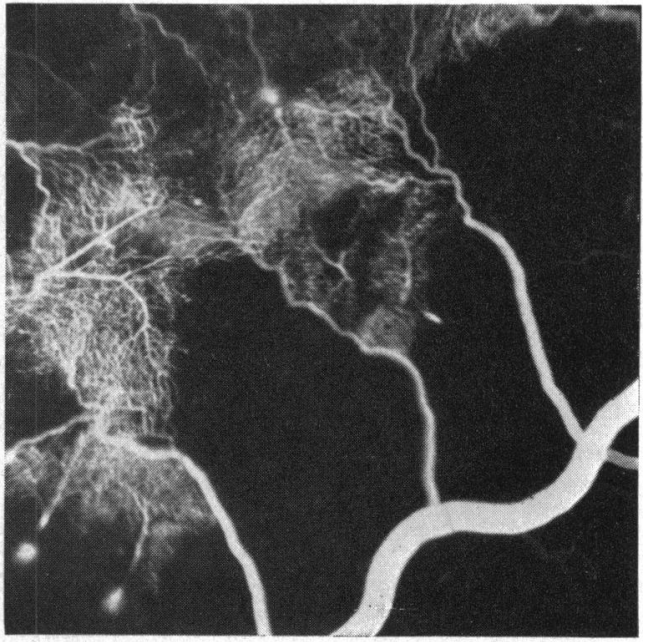

Plate 6.-Pig 30. Two seconds after Plate 5. The normal capillary bed has emptied but many of the capillaries in the area of the cotton-wool spots are patent and have filled late via collaterals. 
Haemorrhage and Cotton-wool Spots at 4 Days

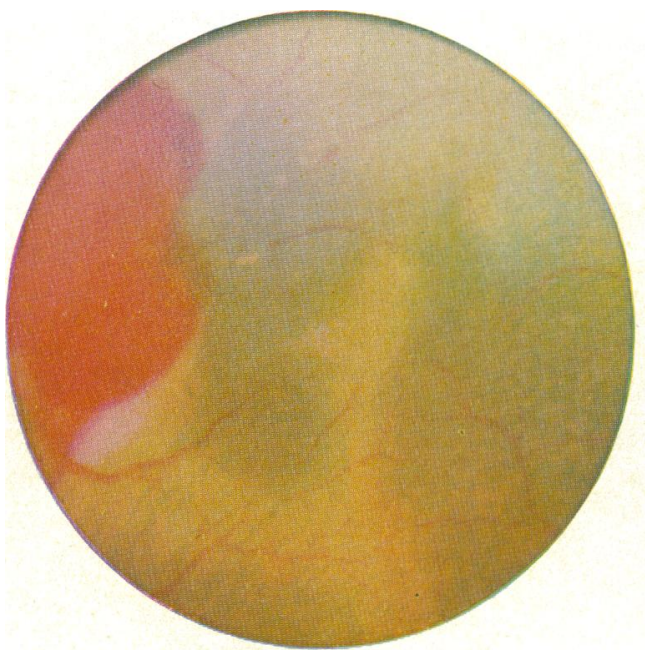

Plate 8.-Pig 25. Four days after embolization, showing a large haemorrhage and resolving white areas of cotton-wool spot.

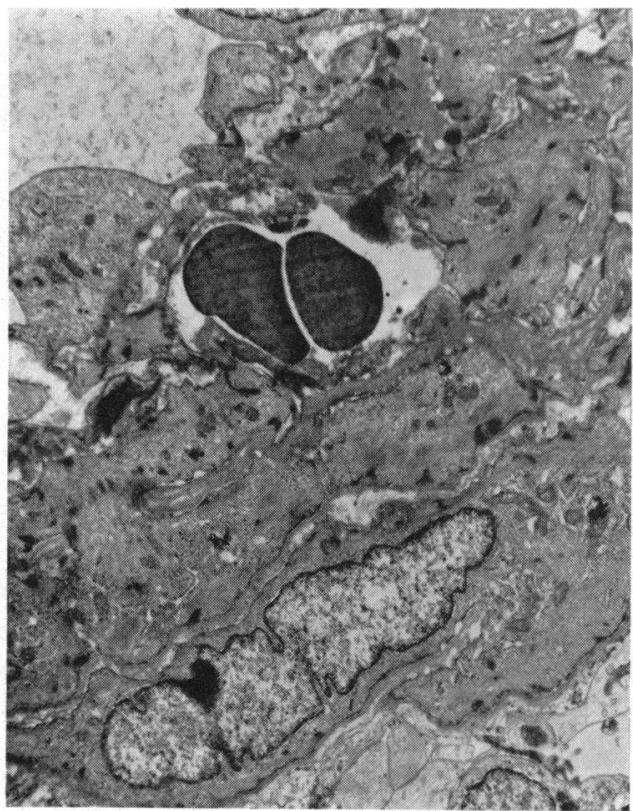

Plate 10.-Pig 25. Electron micrograph showing erythrocytes and fibrin in the wall of the damaged arteriole. $\times 2,300$.

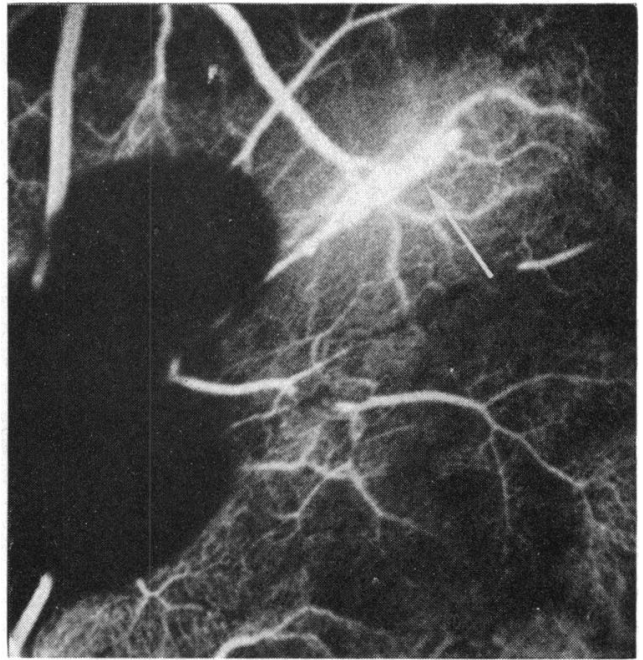

Plate 9.-Pig 25. Fluorescence angiogram (6.4 seconds) of same area as Plate 8 showing dark area of haemorrhage on left and much leakage of dye from a blocked arteriole (arrow). Larger diameter collaterals are present around some of the emboli.

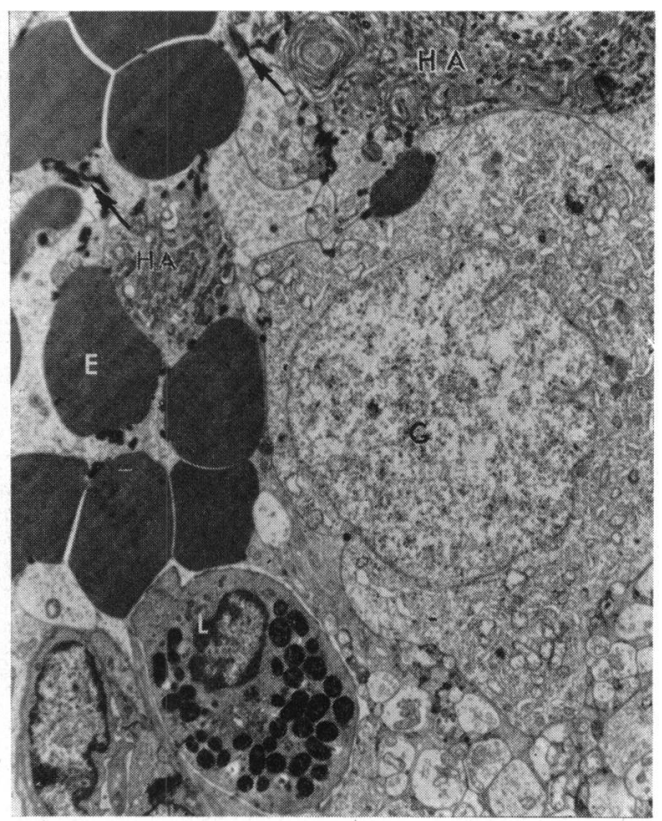

Plate 11.-Pig 25. Electron micrograph of the inner layer of retina showing erythrocytes (E), leucocytes (L), and fibrin (arrows) in the extracellular space adjacent to a swollen hypertrophic axon (HA). G, ganglion cell. $\times 2,250$. 
Cotton-wool Spot at 7 Days

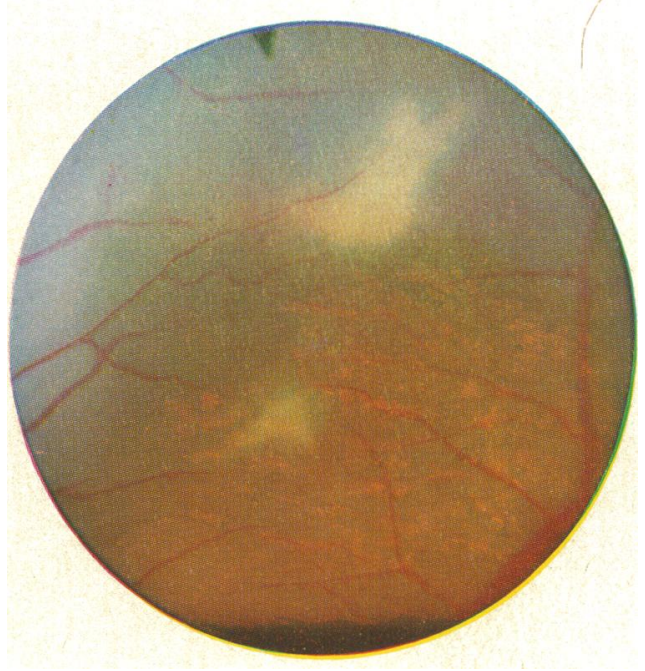

Plate 12.-Pig 24. Two cotton-wool spots are present 3 days after embolization.

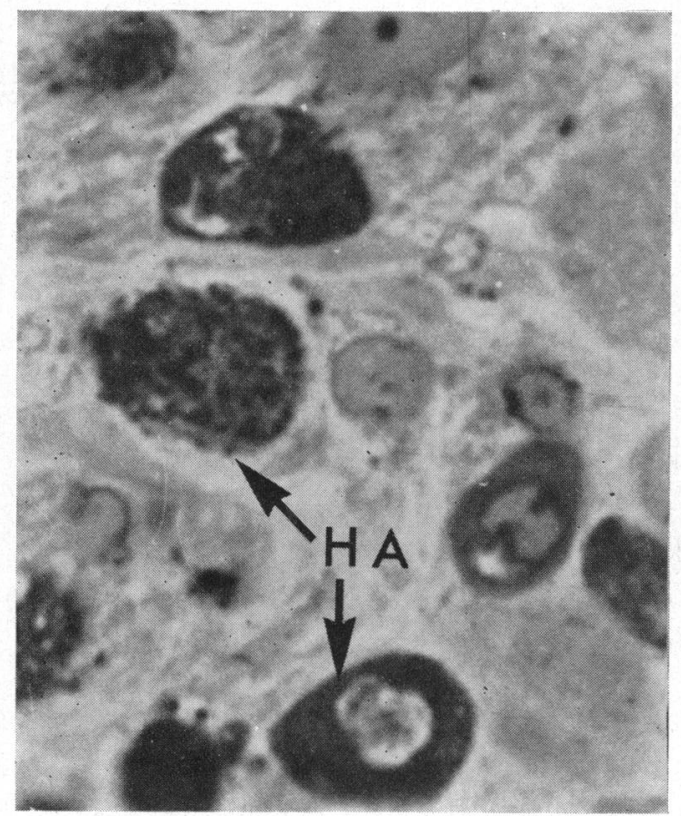

Plate 14.-Pig 24. Photomicrograph showing degenerated hypertrophic axons (HA) in the nerve fibre layer. $\times 1,400$.

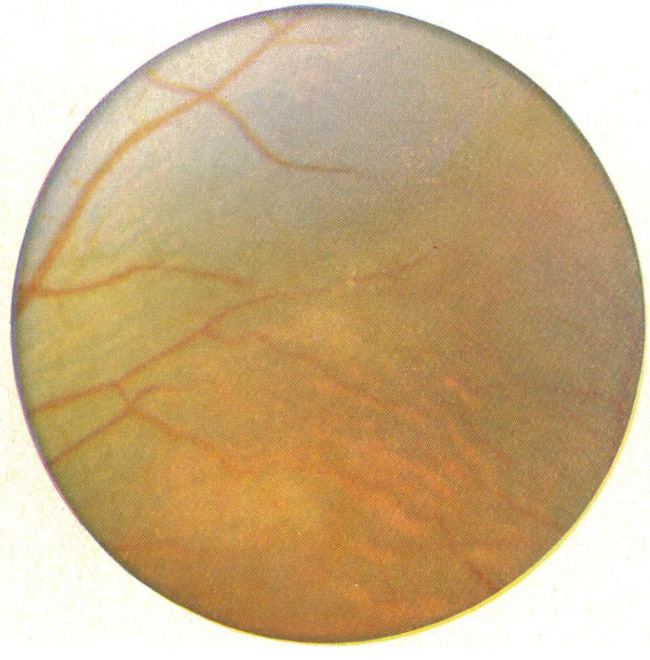

Plate 13.-Pig 24. As Plate 12, 7 days after embolization, showing a faint white granular haze in the area of the cotton-wool spots.

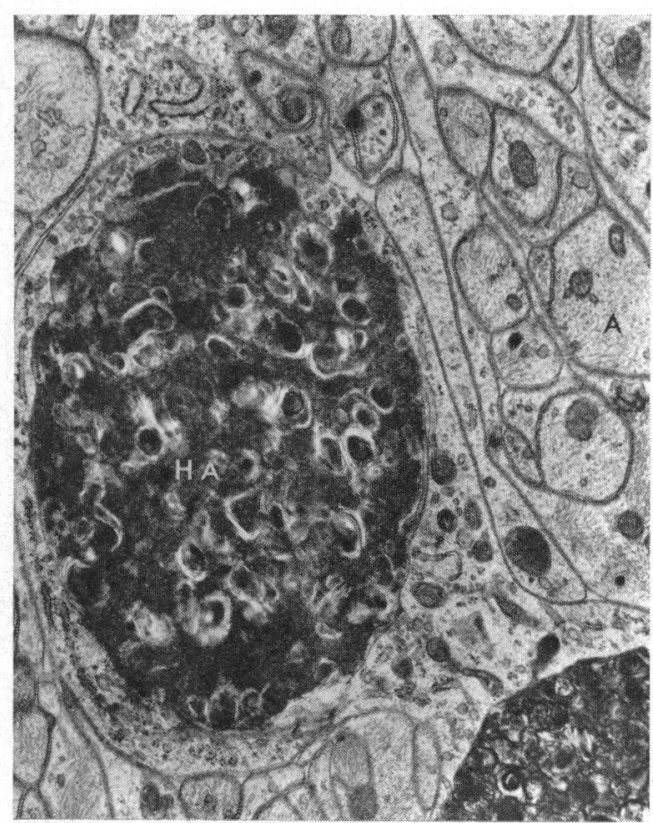

Plate 15.-Pig 24. Electron micrograph showing a degenerated hypertrophic axon (HA) engulfed by a macrophage. A, normal axon. $\times 12,000$. 


\section{Cotton-wool Spot after 14 Days}

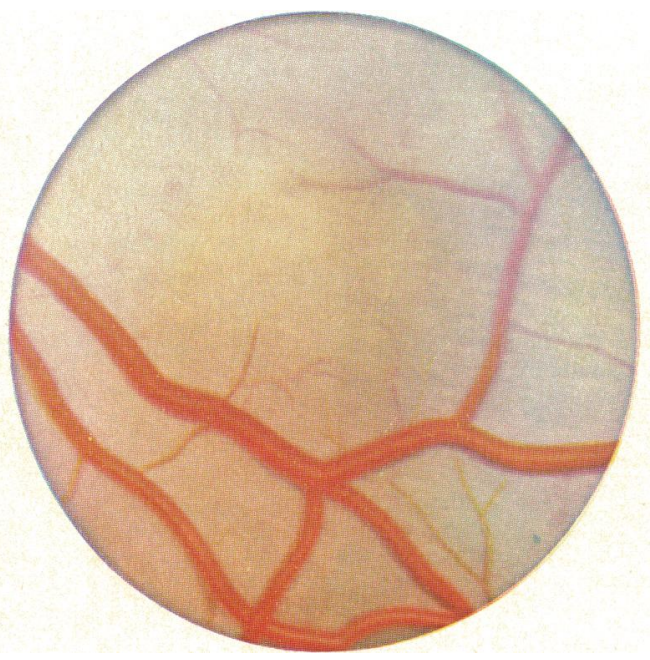

Plate 16.-Pig 40. A multi-embolized area at 4 days containing a granular resolving cotton-wool spot.

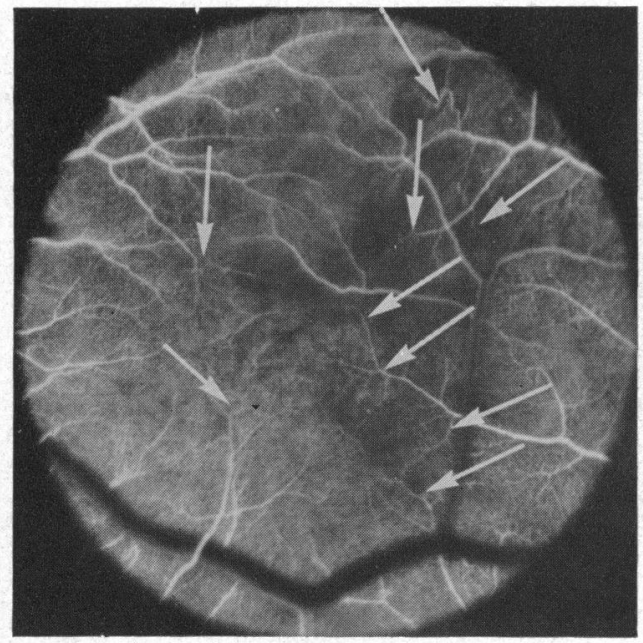

Plate 18.-Pig 40. Fluorescence angiogram (1.9 seconds) 14 days after embolization (cf. Plate 17). Despite the many emboli (arrows) collateral flow is so effective that there is only slight delay in filling.

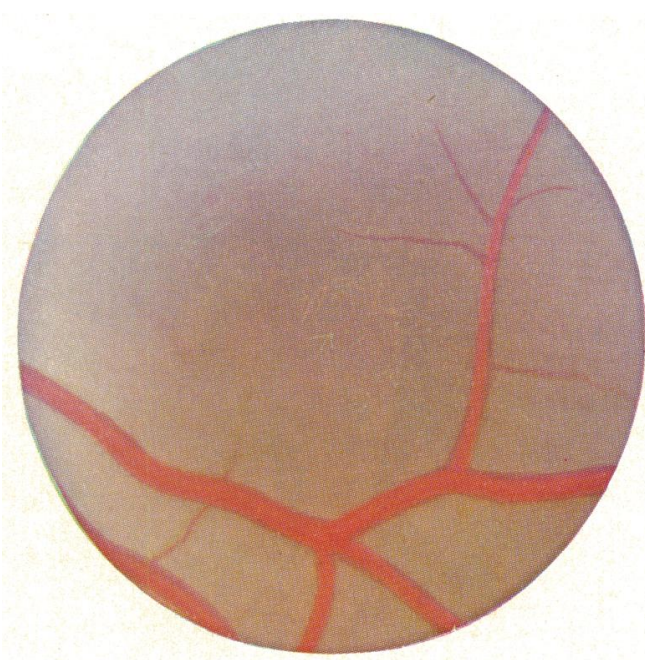

Plate 17.-Pig 40. As Plate 16, 14 days after embolization, showing that the cotton-wool spot has almost resolved.

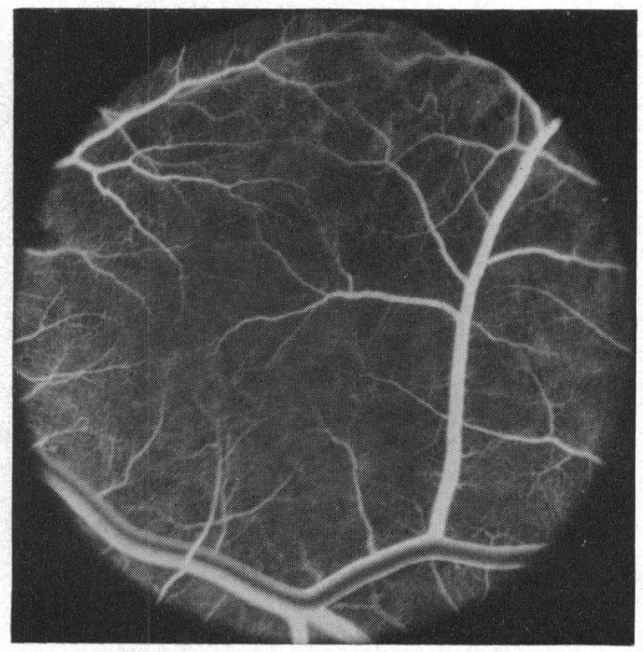

Plate 19.-Pig 40. One second later than Plate 18 , perfusion appears normal. 


\section{Cotton-wool Spot after 14 Days-continued}

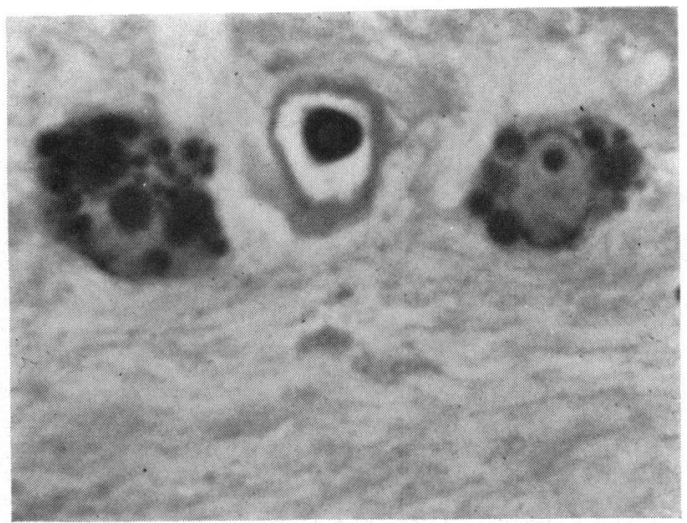

Plate 20.-Pig 40. Photomicrograph of degenerated hypertropic axons in macrophages. $\times 1,150$.

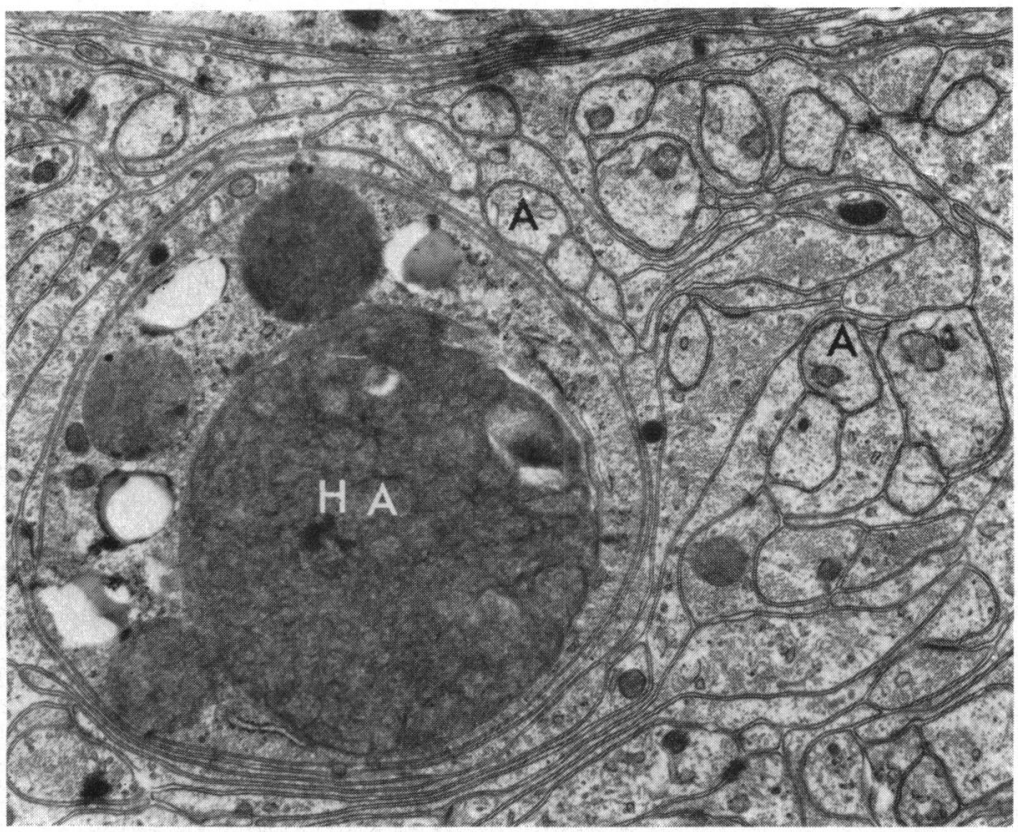




\section{Cotton-wool Spot Colour Sequence}

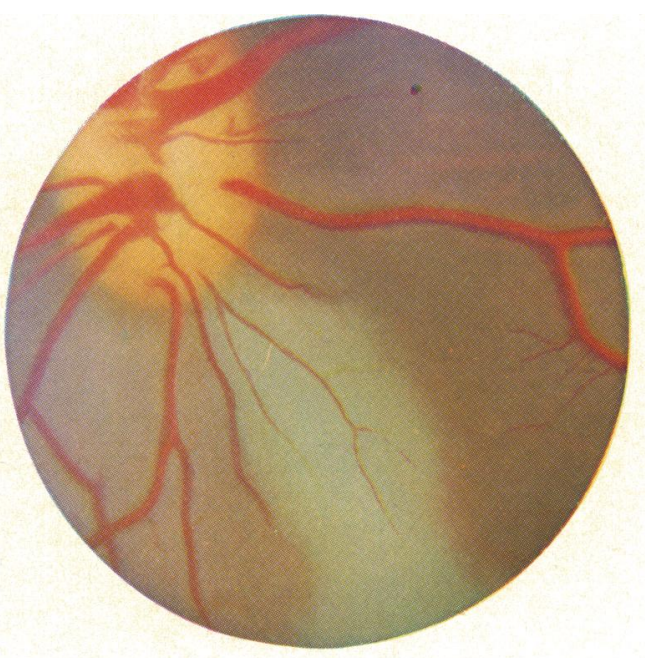

Plate 22.-Pig 46. Twenty-seven minutes after embolization of a small artery on the optic disc the retina downstream has turned a greyish-white colour.

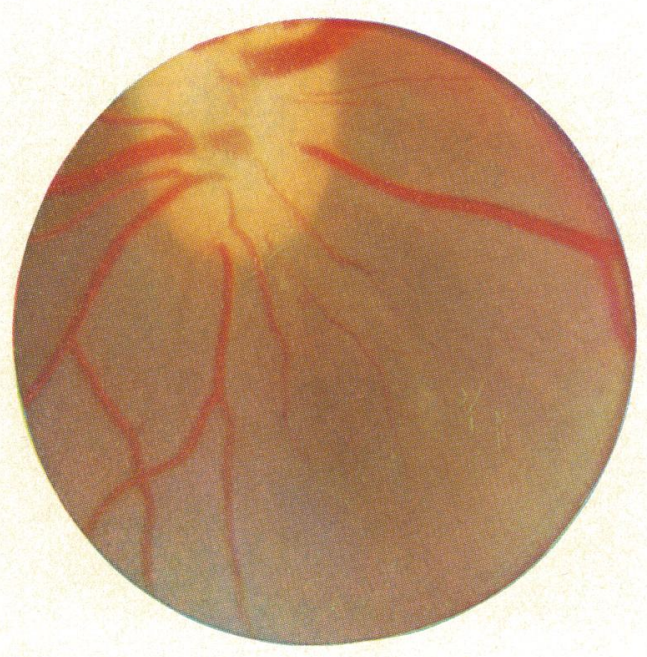

Plate 24.-Pig 46. As Plates 22 and 23. Ten days after embolization, only a few white flecks remain in the area of the cotton-wool spot.

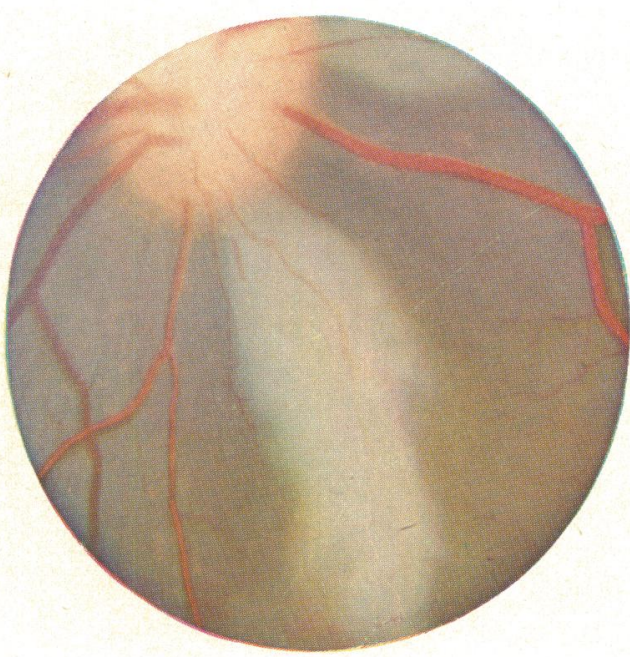

Plate 23.-Pig 46. As Plate 22 but 48 hours later. A cotton-wool spot occupies the area of the greyish discoloration. A glass sphere has moved and is visible in one of the main branches of the artery that was obstructed in Plate 22.

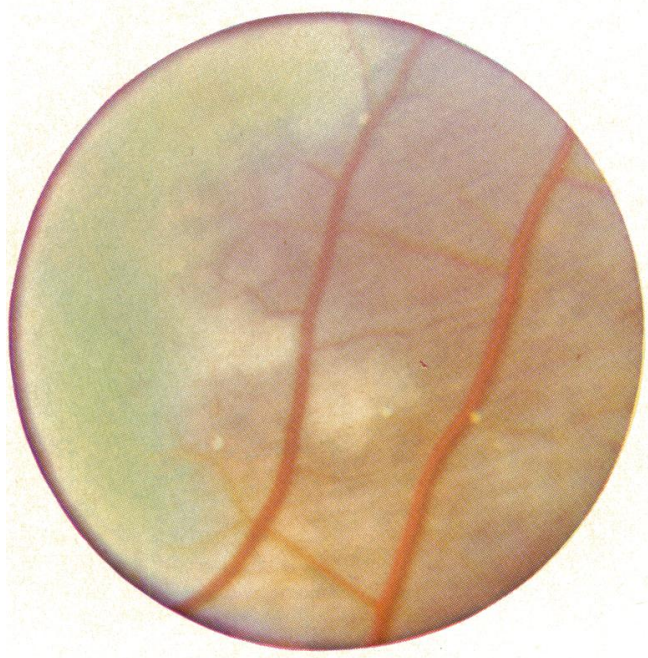

Plate 25.-Pig 46. Nasal retina of the same pig as Plate 23, 48 hours after embolization. Only a faint white haze has appeared in this area where the collateral flow was better. The arteriole proximal to the uppermost glass sphere is reduced to a white thread. 


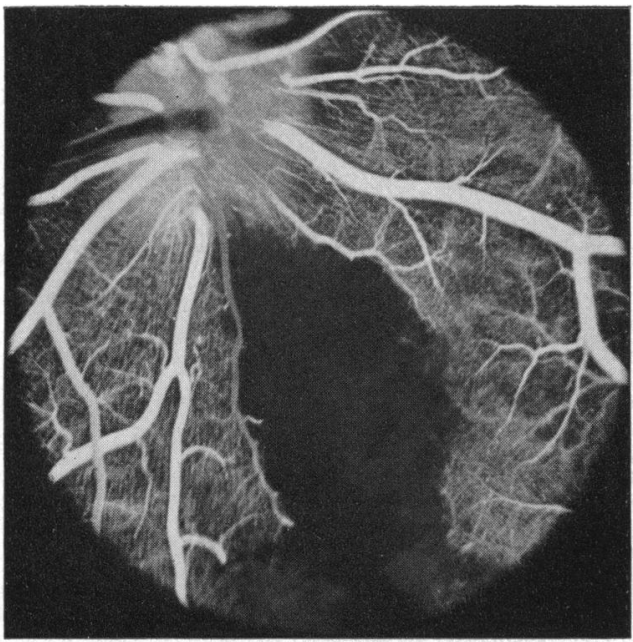

Plate 26.-Pig 46. Fluorescence angiogram 37 minutes after injection of emboli. The vascular bed downstream to the embolus is not filled with dye.

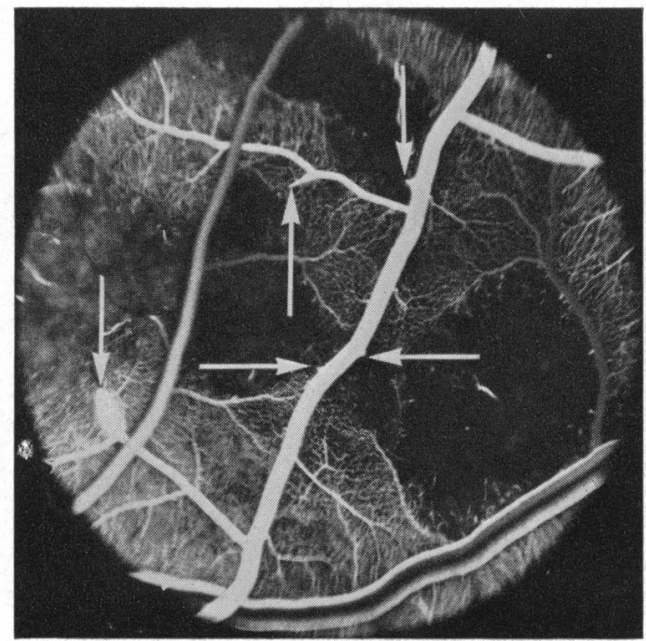

Plate 28.-Pig 46. Same eye as Plates 26 and 27. Nasal retina 41 minutes after embolization showing non-perfused areas downstream to emboli (arrows). One arteriole (arrow, left) shows dye leakage.

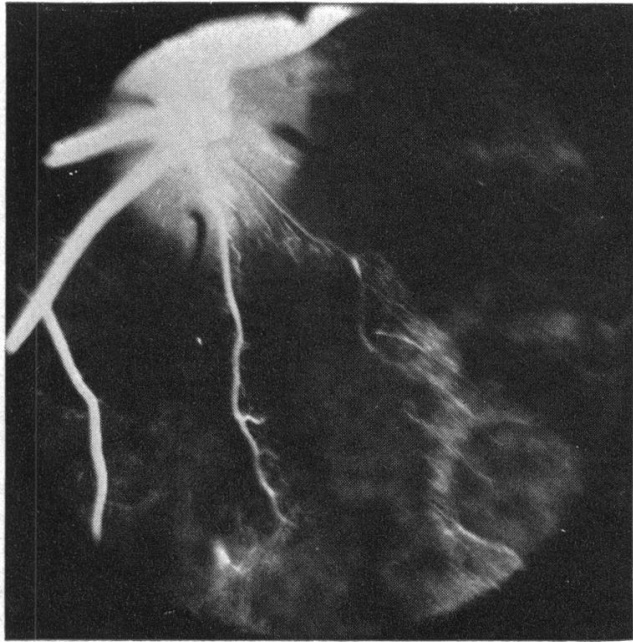

Plate 27.-Pig 46. As Plate 26 but 6 seconds later. Only $a$ thin and ineffective rim of collaterals filled at any stage and a cotton-wool spot was present 48 hours later (Colour Plates 22 and 23).

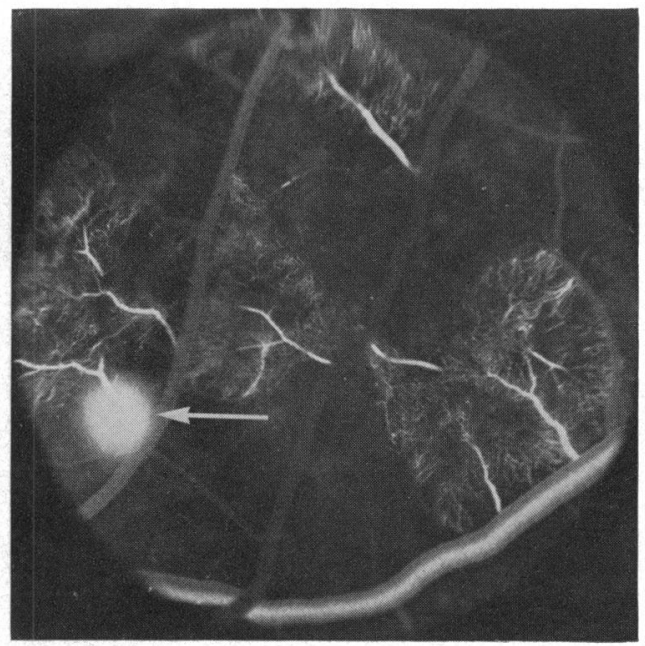

Plate 29.-Pig 46. As Plate 28 but 22 seconds later. The blocked segments of arteriole have filled completely through capillary collaterals. Only a faint white haze appeared in these areas on colour photographs taken $\mathbf{4 8}$ hours later (Plate 25). Note the leakage of dye (arrow) and the patency of the capillary bed surrounding it (cf. Plate 28). 
Flow Changes immediately after Injection of Emboli

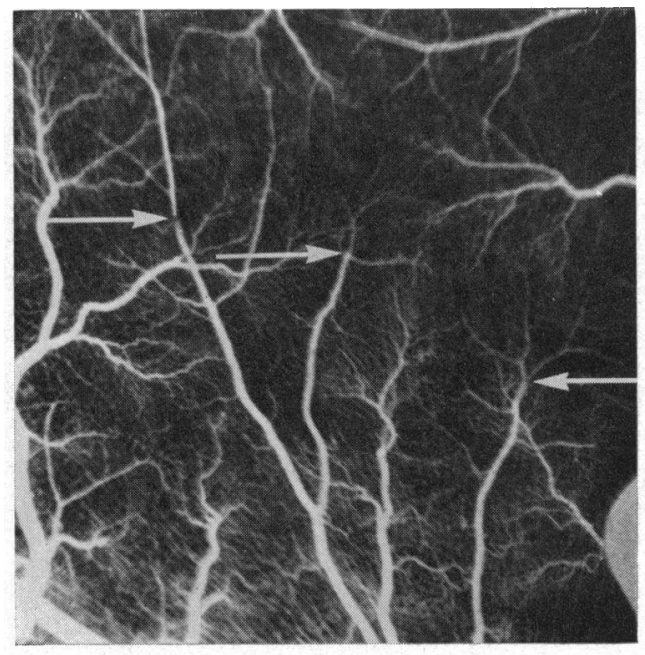

Plate 30.-Pig 30. Angiogram during injection of ballotini with fluorescein. Emboli are visible as minute breaks in the fluorescent blood column (arrows).

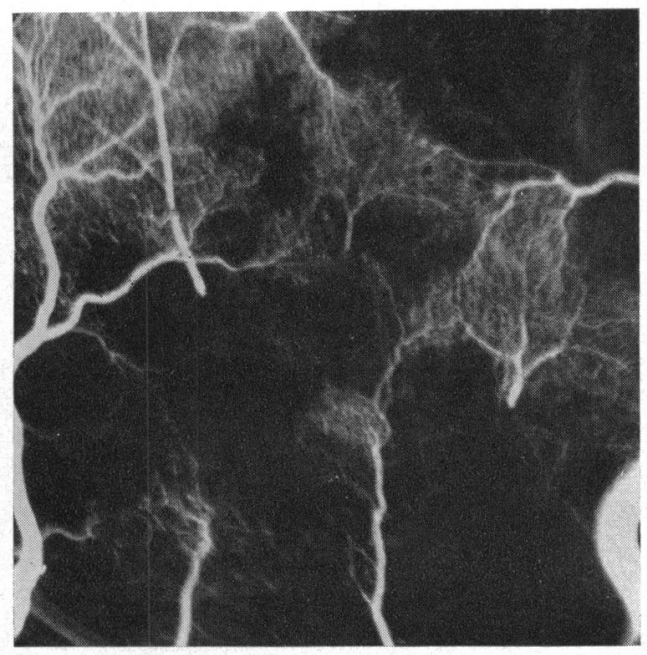

Plate 31.-Pig 30. As Plate 30, 5 seconds after stopping dye injection. Beyond the emboli the fluorescent blood persists. Arterioles downstream from emboli are patent. Later dye emptied slowly from the periphery.

\section{Effects of Multiple Embolization on Flow Changes}

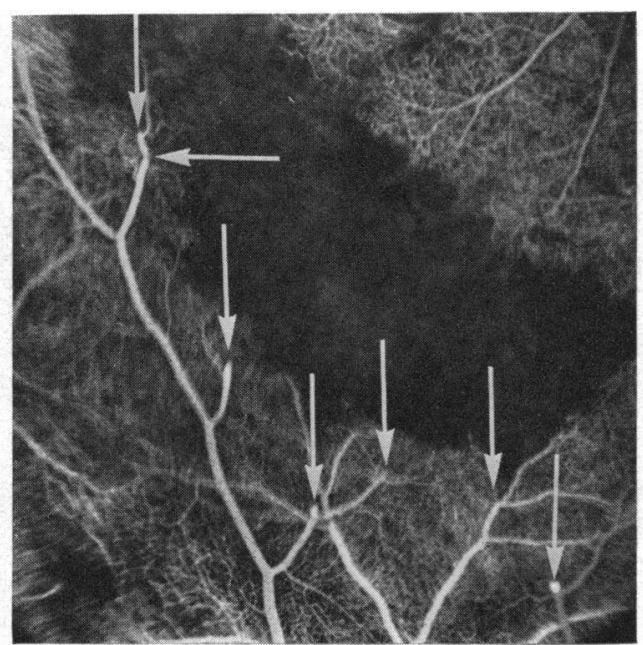

Plate 32.-Pig 31. Capillary phase fluorescence angiogram 1 minute after embolization. Many arterioles are occluded (arrows) and the capillary bed is not perfused.

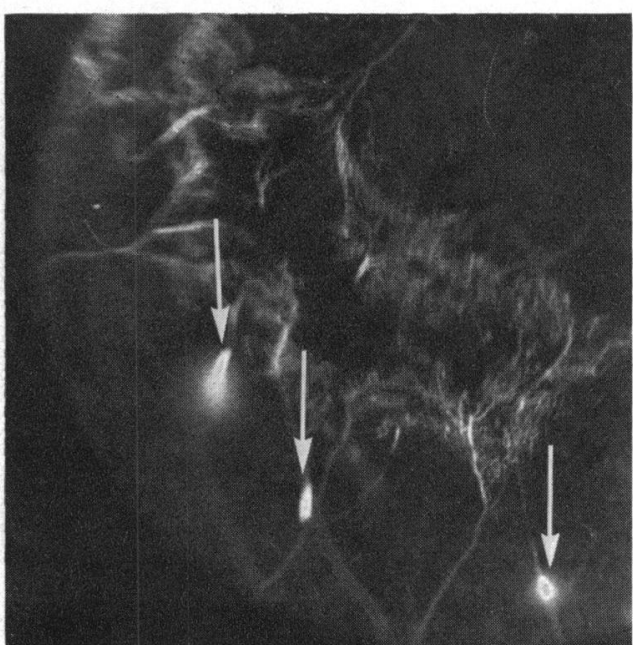

Plate 33.-Pig 31. As Plate 32, 8.7 seconds later. Dye is leaking at the site of several emboli (arrows). Very slow and incomplete capillary collateral infilling is taking place at a rate of less than $0.1 \mathrm{~mm}$. per second. 


\section{Flow Changes after Embolization}

\section{Capillary Collateral Flow}

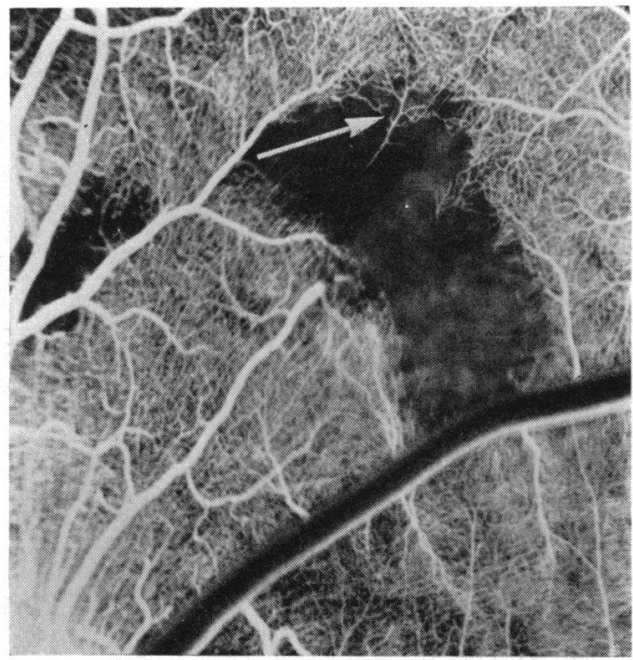

Plate 34.-Pig 24. Capillary phase (2.6 seconds) fluorescence angiogram 35 minutes after embolization. Fine collateral twigs (arrow) are beginning to fill the dark area from its edge.

\section{Seven Days after Embolization}

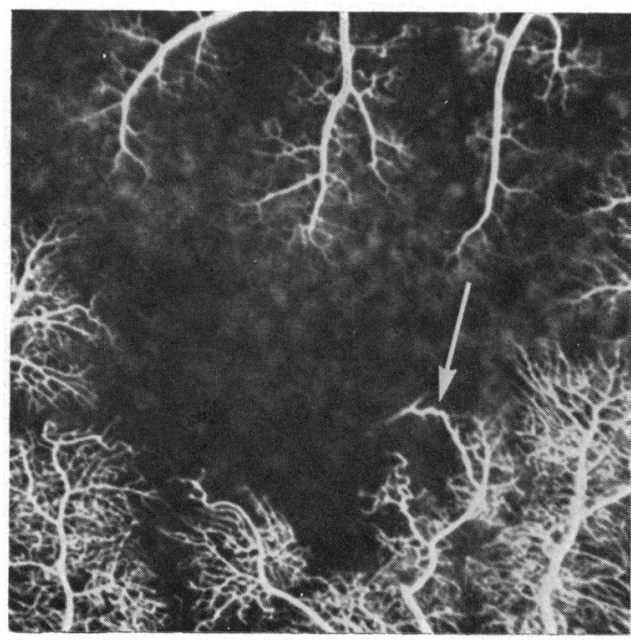

Plate 36.-Pig 24. Capillary phase (1.8 seconds) fluorescence angiogram 7 days after embolization showing a larger diameter collateral (arrow).

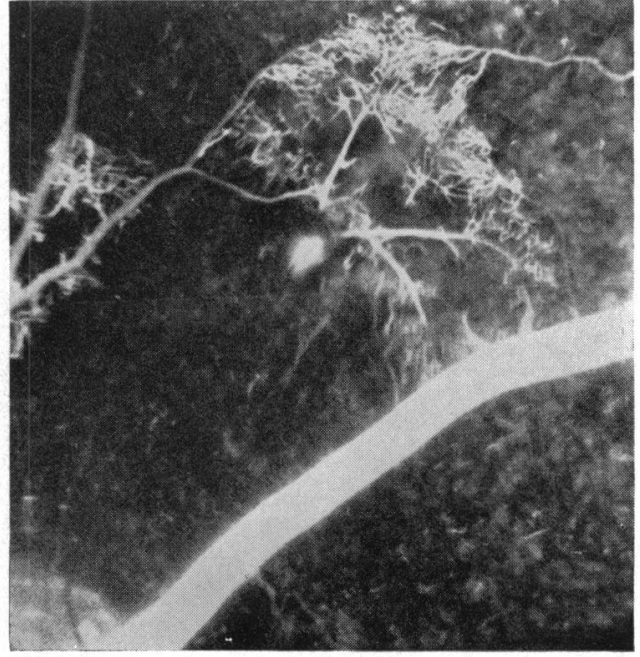

Plate 35.-Pig 24. As in Plate 34 but 4 seconds later. Capillary collaterals are filling the whole of the vascular bed downstream to the embolus at a rate of about $2 \mathrm{~mm}$./sec.

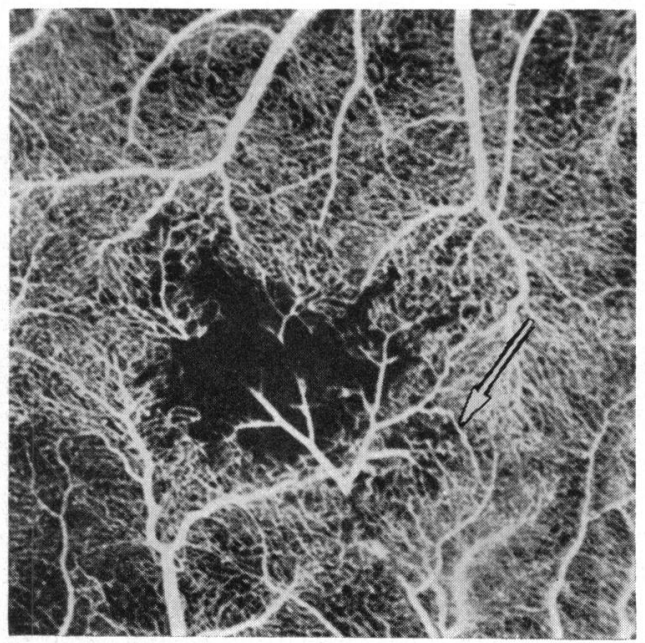

Plate 37.-Pig 24. As in Plate 36 but $3 \cdot 2$ seconds later. The proximal part of the arteriole is filling through the collateral (arrow) at about $6 \mathrm{~mm}$. $/ \mathrm{sec}$. The distal arteriole still fills via capillaries. 


\section{Flow Changes after Embolization}

Fourteen Days after Embolization

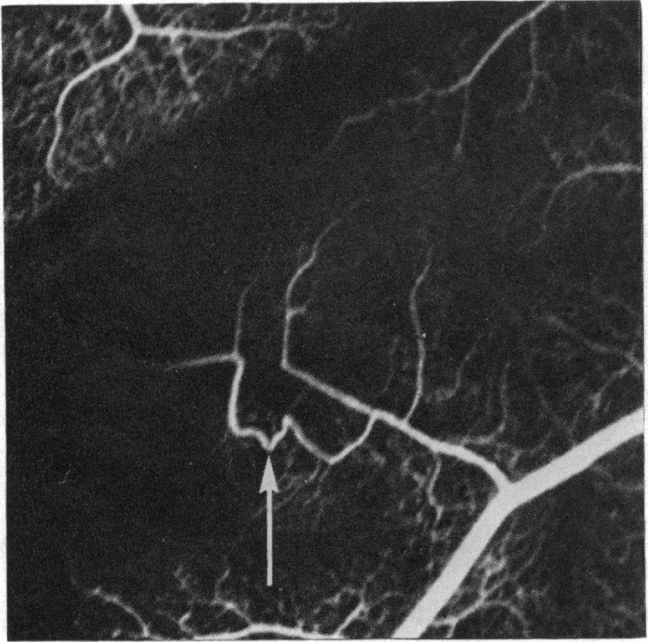

Plate 38.-Pig 27. Arterial phase fluorescence angiogram 14 days after embolization. A large collateral (arrow) bridges the blocked segment.

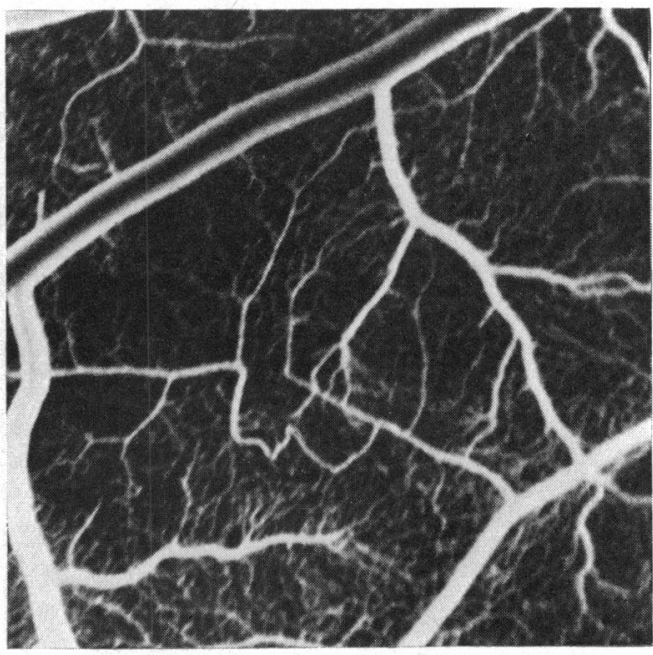

Plate 39.-Pig 27. As in Plate 38, one second later. There is little delay in capillary perfusion beyond the embolus.

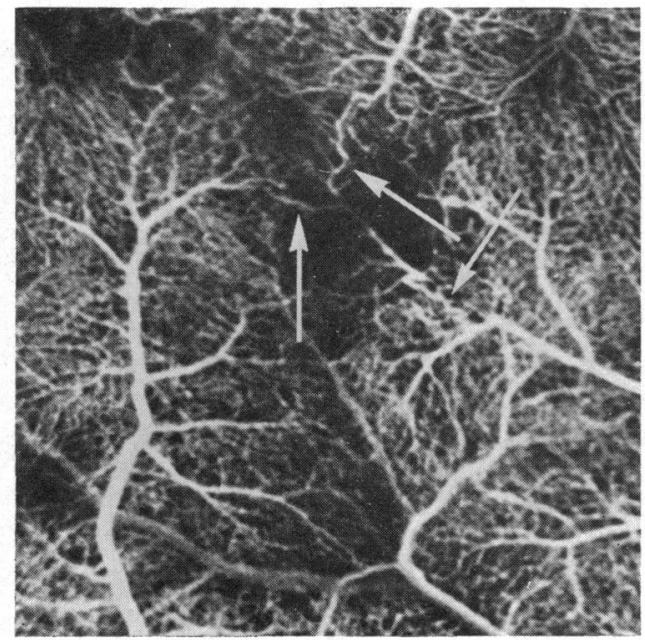

Plate 40.-Pig 29. Thirty-eight days after embolization. Three collaterals are present (arrows).

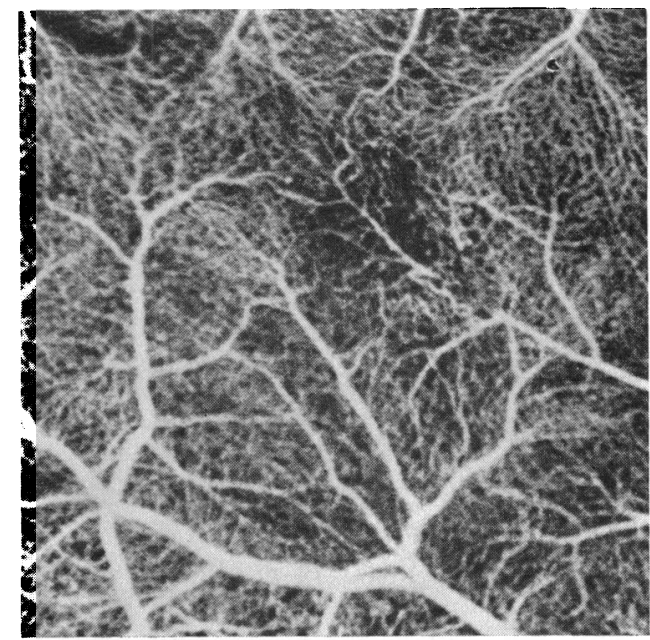

Plate 41.-Pig 29. As in Plate 40 but 1 second later. The capillary bed throughout the retina is filled. 


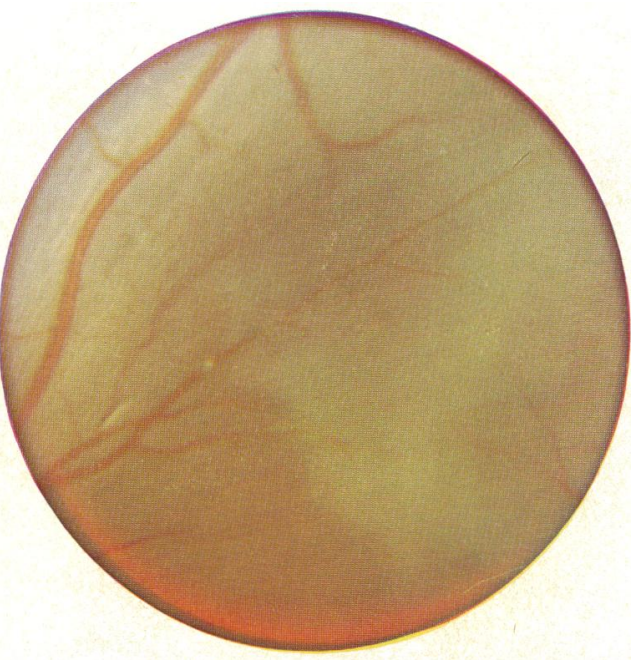

Plate 42.-Pig 37. Twenty-one minutes after embolization of a large arteriole the blood column is broken and dark and the retina has developed a greyish-white haze.

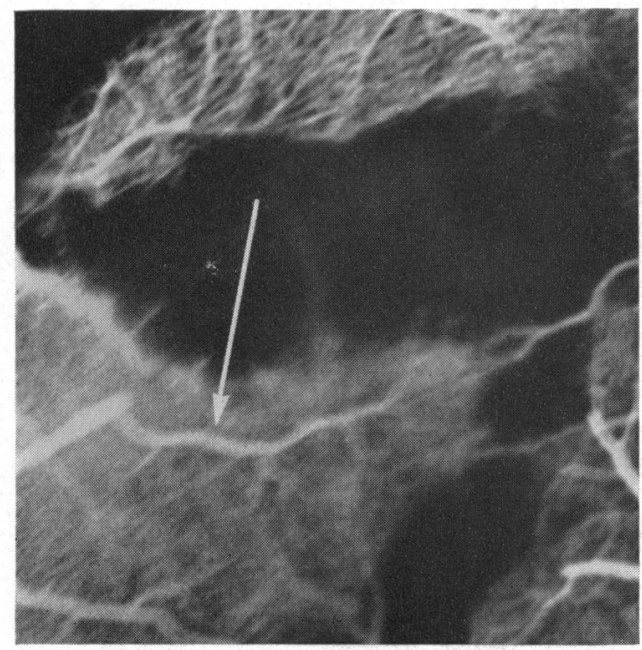

Plate 44.-Pig 37. Fluorescence angiogram, in close-up, of the large cotton-wool spot in Plate 43. The capillary bed downstream to the embolus is not perfused at this stage but the area of cottonwool spot supplied by the re-opened arteriole (arrow) is perfused.

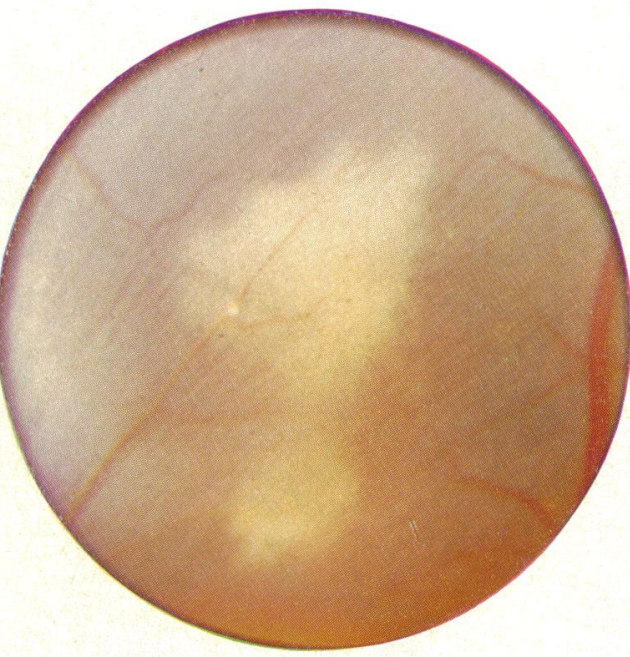

Plate 43.-Pig 37. As in Plate 42, twenty-four hours later a large cotton-wool spot has formed. The largest embolus has moved distally and reopened the arteriole to part of the cotton-wool spot.

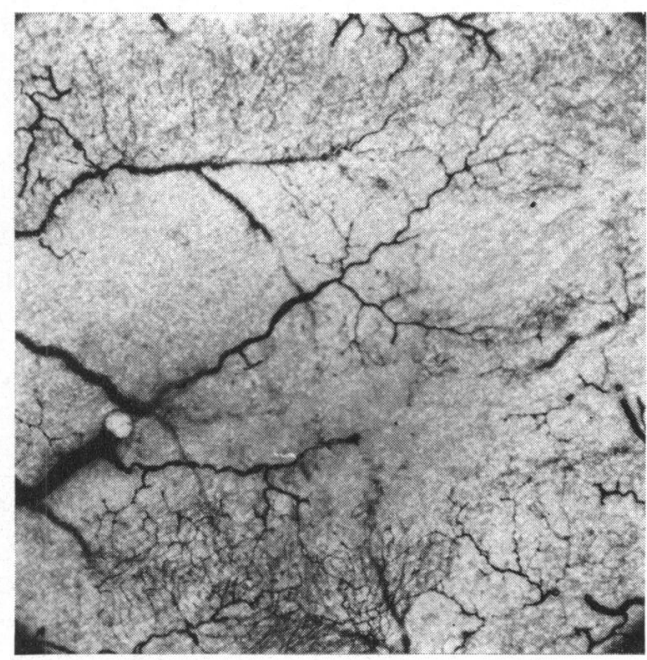

Plate 45.-Pig 37. Indian ink injection of the same area as Plate 44 . The Indian ink has penetrated into the distal part of the blocked arteriole through capillary collaterals which were also shown on later fluorescence photographs. Capillary filling in the area of the cotton-wool spot is not complete. 
Capillary Collateral Flow: Comparison of Fluorescence and Ink Studies

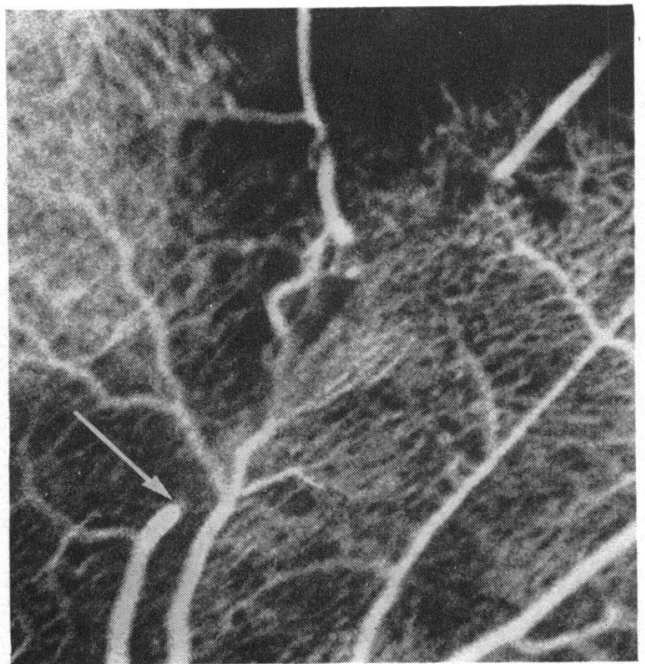

Plate 47.-Pig 30. As Plate 46 but 3.6 seconds later. Complete collateral in-filling of the vessels downstream to the embolus has taken place. A greater number of capillaries are visible on the angiogram than on the Indian ink injection.

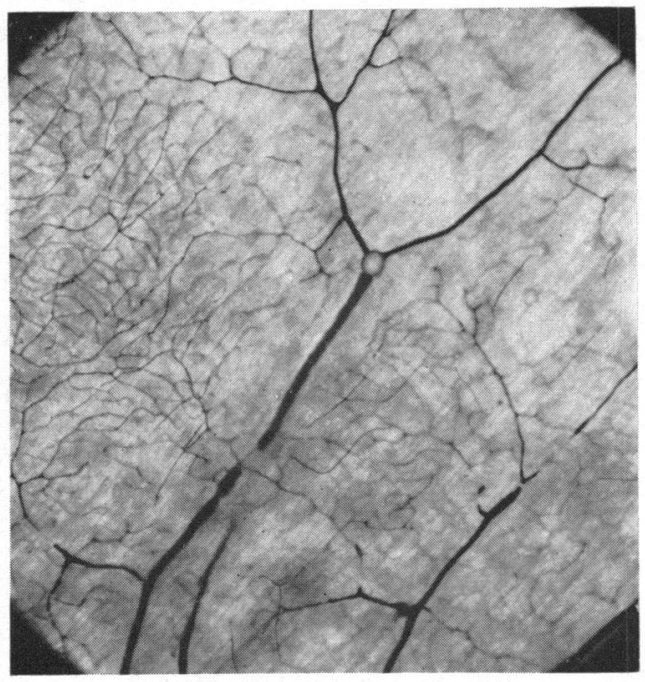

Plate 46.-Pig 30. Capillary phase ( $4 \cdot 7$ seconds) fluorescence angiogram 11 minutes after embolization (arrow). The distal segment of the blocked arteriole is filling through capillary collaterals.

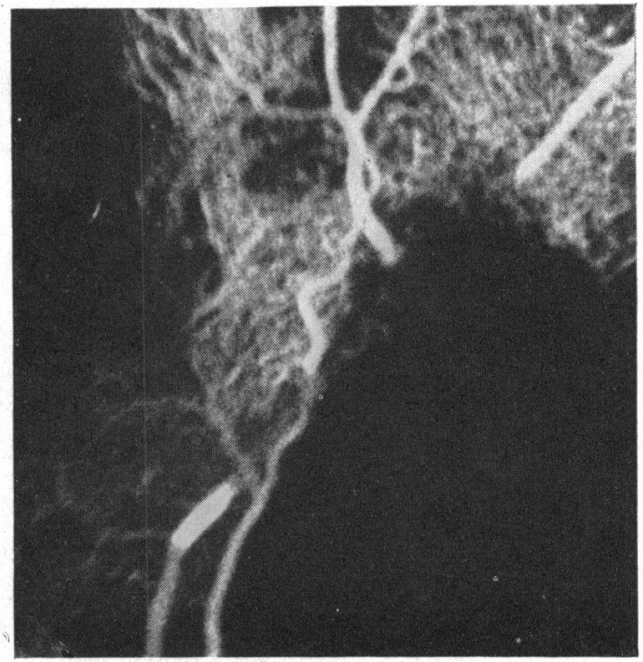

Plate 48.-Pig 30. Indian ink injection 1 hour after embolization (49 minutes after Plates 46 and 47). The main arteriole distal to the embolus has filled through capillary collaterals. 
Collaterals at 35 Days

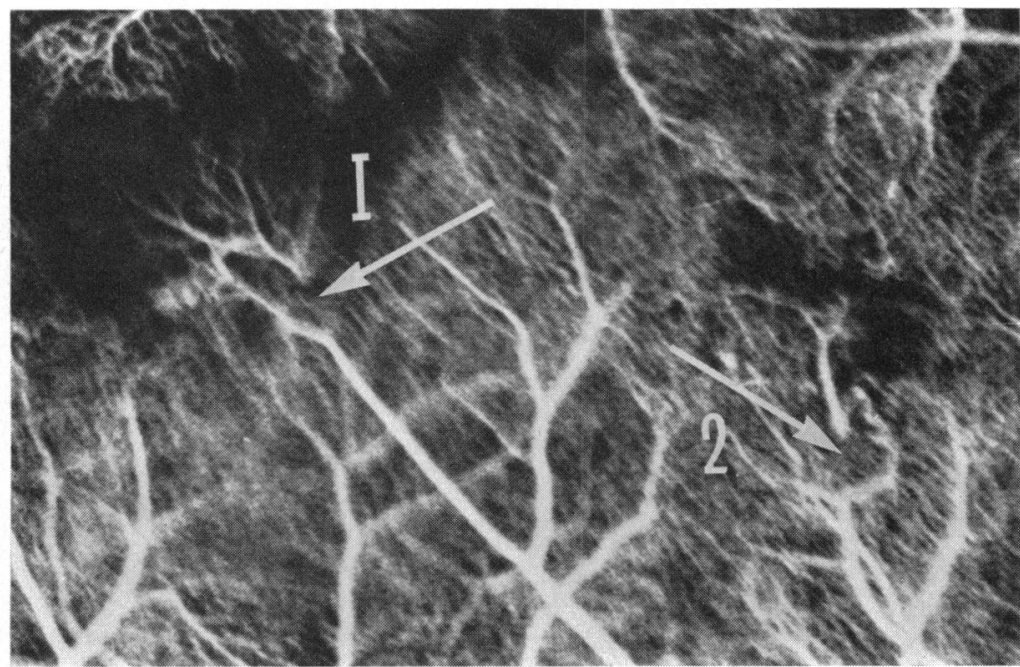

Plate 49.-Pig 31. Fluorescence angiogram of an area embolized 35 days before. Two blocked segments of arteriole are by-passed by collaterals (arrows 1 and 2).

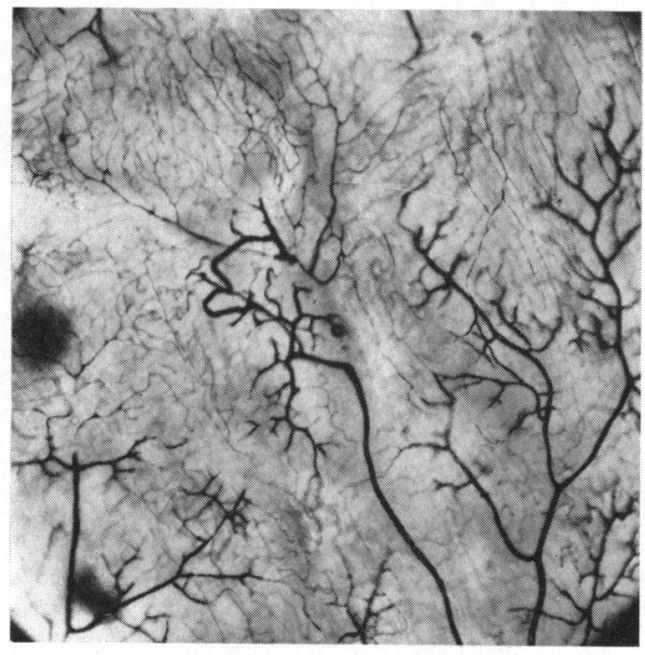

Plate 50.-Pig 31. Indian ink injection study of the collateral (1) in Plate 49.

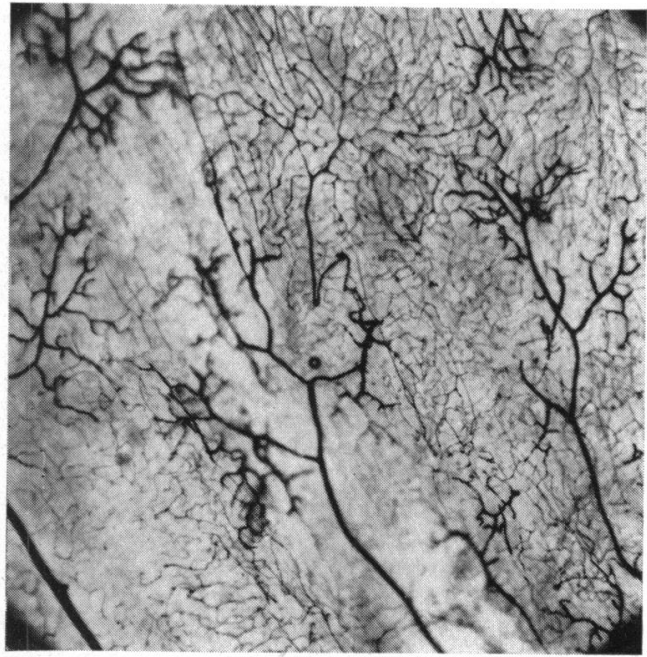

Plate 51.-Pig 31. Indian ink study of the second collateral shown in Plate 49. More detail is visible on these Indian ink injection studies than in the fluorescence angiogram. 